\title{
Ethical Attribute and Brand Concept Congruity Enhances Brand Evaluations
}

Maryam Tofighi, Onur Bodur, and Bianca Grohmann

To cite this article: Tofighi, Maryam, Onur Bodur, and Bianca Grohmann (2019), "Ethical Attribute and Brand Concept Congruity Enhances Brand Evaluations," European Journal of Marketing, 54 (1), 79 - 108. doi: 10.1108/EJM-02-2018-0104

To link to this article: https://doi.org/10.1108/EJM-02-2018-0104 


\section{Ethical Attribute and Brand Concept Congruity Enhances Brand Evaluations}

\section{Structured Abstract:}

Purpose: This research examines to what extent congruity between ethical attributes (i.e., product attributes with positive implications for the environment, human rights, social issues, and animal welfare) and brand concept (i.e., the unique meaning associated with a brand in consumers' minds) influences consumers' evaluations of brands offering ethical attributes.

Design/methodology/approach: Four studies involving North American consumers empirically tested the moderation effect of brand concept on consumer evaluations of ethical attributes and the mediating role of perceived congruity.

Findings: This research finds an interactive effect of ethical attribute type and brand concept on brand evaluations, such that congruent ethical attribute-brand concept pairings (i.e., a utilitarian [symbolic] ethical attribute offered by a brand with a utilitarian [symbolic] brand concept) result in more favorable brand evaluations (Studies 1, 2, 3, and 4). Consumers' perceptions of congruity between ethical attributes and brand concepts mediate this interactive effect (Studies 2 and 3). Moreover, a positive congruity effect of ethical attributes and brand concepts emerges at higher levels of conspicuous brand consumption (Study 4).

Practical implications: For marketing managers, findings indicate that brands gain from ethical attribute introductions only when these attributes are congruent with the brand concept. In addition, brands benefit to a greater extent from offering congruent ethical attributes when brand consumption is conspicuous.

Originality/value: The findings of this research contribute to the literature on the effect of ethical attributes on consumers' responses to brands and highlight the importance of brands' choice of ethical attributes.

Keywords: ethical attributes; sustainable brands; brand concept; conspicuous consumption; perceived congruity; social responsibility. 


\section{Introduction}

Under the guidance of its former CEO Indra Nooyi, Pepsi Co. introduced Pepsi Nextan aspartame-free cola beverage brand. This introduction coincided with a strategic modification of Pepsi Co.'s brand portfolio through the acquisition of brands associated with health benefits, such as Tropicana and Quaker Oats. In introducing its new brand and adding brands associated with health benefits, Pepsi Co. sought to contribute to consumers' long-term well-being (Chatterji, 2013). Although Pepsi Co.'s strategy was initially praised in the media (Seabrook, 2011), Pepsi Co.'s stock prices stagnated, while Coca Cola's doubled (Chatterji, 2013).

The lack of a positive consumer response to Pepsi Co.'s offering of ethical attributes supporting consumers' long-term health appears counterintuitive, and raises several questions: Is it possible that consumers perceive a lack of congruity between Pepsi Co.'s brand positioningwhich is highly symbolic and conveys excitement (Aaker, 1997) — and the introduction of ethical attributes that have functional implications for consumer health? Does this apparent contradiction negatively influence consumers' evaluations of the brand?

Emerging evidence indeed suggests that consumer responses to brands offering ethical attributes are contingent upon contextual factors, such as consumers' familiarity with the brand (Arora and Henderson, 2007), values conveyed by the brand (Torelli et al., 2012), or extrinsic brand quality cues (Bodur et al., 2016). To shed light on factors that influence consumers' evaluation of brands offering ethical attributes, this article examines the effect of congruity between symbolic and utilitarian ethical attributes (Bodur et al., 2014) and symbolic and utilitarian brand concepts (Aaker, 1997; Keller, 1993; Park et al., 1986, 1991).

Brand concepts capture the unique meaning associated with a brand in consumers' minds (Keller, 1993; Park et al., 1986, 1991). A symbolic brand concept allows consumers to self- 
express, convey prestige or signal group membership, whereas a utilitarian brand concept emphasizes functionality or performance (Keller, 1993; Wilcox et al., 2009). Brands seek to distinguish themselves from competing brands within the same product category by choosing unique and differentiated brand concepts (Keller, 1993; Park et al., 1986, 1991). Similarly, brands compete by offering diverse ethical attributes. Utilitarian ethical attributes relate to ingredients or functionality, whereas symbolic ethical attributes signal non-product based ethicality, such as cause support (Bodur et al., 2014).

Research suggests that the nature of ethical attributes influences consumer evaluations at the product category level, such that symbolic (utilitarian) ethical attributes are perceived more positively when they are associated with symbolic (utilitarian) products (Bodur et al., 2014). Product level findings may be of limited value to decision making at the brand level, however. This is because the need for brand differentiation leads to a diversity of brand concepts within a given product category, which results in varying levels of congruity of a given functional and symbolic ethical attribute in relation to the brands competing within the category. This means that product category level findings do not apply to the same extent to the brands pursing different positioning strategies within the category. Overall, it is therefore not clear to what extent and under what circumstances product-level findings regarding ethical attribute congruity extend to the brand level.

An investigation of brand-level congruity effects in the context of ethical attributes is also useful because the literature on congruity effects at the brand level is characterized by inconsistent findings. Research indicates that, while congruity between persuasive appeals and product categories in terms of functionality or symbolism resulted in higher levels of persuasion, positive congruity effects did not emerge at the brand level (LeBoeuf and Simmons, 2010). 
Importantly, the presence of brand cues decreased the magnitude of the congruity effects observed at the product level (LeBoeuf and Simmons, 2010). Other research finds positive congruity effects for utilitarian— but not hedonic — persuasive appeals and product category benefits on advertisement and brand evaluations (Bodur and Grohmann, 2004).

Against this backdrop, the current article makes the following contributions to the literature: First, it develops theoretically grounded predictions regarding the interaction of ethical attributes and brand concept types drawing on congruity theory. Second, the current research empirically tests ethical attribute - brand concept congruity effects. In doing so, this article clarifies whether and to what extent congruity effects involving ethical attributes operate at the brand level. Third, this research specifically investigates the mediating role of consumers' congruity perceptions to document the congruity process underlying the interaction effect of ethical attributes and brand concepts. Finally, to shed light on contextual factors that might be driving some of the contradictory findings observed in the literature on congruity effects, this article explores the role of conspicuousness in the attribute type - brand concept congruity relation.

The article is structured as follows: First, by drawing on congruity theory, it derives predictions regarding the effects of congruity of brand concepts and ethical attributes on consumers' brand evaluations. Four studies then test the interaction between brand concept and ethical attribute types in influencing consumers' brand evaluations (Studies 1, 2, 3, and 4) and the mediating role of perceived congruity between brand concept and ethical attribute type (Studies 2 and 3). A final study (Study 4) explores conspicuousness of brand consumption as a boundary condition to the observed effects of ethical attribute - brand concept congruity. 
In line with congruity theory, the empirical results indeed support an interactive effect of ethical attribute type and brand concept on consumers' evaluation of brands offering ethical attributes. Congruent ethical attribute-brand concept pairings (i.e., a utilitarian [symbolic] ethical attribute offered by a brand with a utilitarian [symbolic] brand concept) result in more favorable brand evaluations (Studies 1, 2, 3, and 4). Consumers' perceptions of congruity between ethical attributes and brand concepts mediate this interactive effect (Studies 2 and 3). Study 4 then replicates and qualifies the findings of studies 1,2 , and 3 by demonstrating that a positive congruity effect of ethical attributes and brand concepts emerges at higher levels of conspicuous brand consumption (Study 4). These findings complement research on factors influencing the success of ethical attribute offerings by focusing on brand-level ethical attributes and brand concepts. From a managerial standpoint, the findings offer guidelines regarding what types of ethical attributes are most likely to enhance brand evaluations.

\section{Conceptual Background}

\section{Ethical Attributes}

Ethical attributes have positive implications for the environment, human rights, social issues, and animal welfare (Bodur et al., 2016). They are characterized as symbolic (e.g., abolition of child labor, community engagement) or utilitarian (e.g., natural ingredients, lowwaste production, energy-saving technology) (Bodur et al., 2014). In the domain of ethical consumption, utilitarian attributes relate to the product and functionality, whereas symbolic attributes capture meaning that go beyond physical attributes (Banister and Hogg, 2004; Levy, 1959), such as support for a cause (Bodur et al., 2014). 
The literature has defined ethical attributes in terms of product attributes (Bodur et al., 2016). A consideration of consumer responses to product level ethical attributes is important in encouraging regulatory and industry-wide initiatives supporting the introduction of such attributes. The replacement of trans-fats in food products with healthier ingredients, for example, was initially driven by consumer advocacy groups' criticism with regard to associated risks to consumer health; this motivated the voluntary substitution of trans-fats among companies in the consumer packaged food industry in North America (Hallock, 2013). Shortly thereafter, the Food and Drug Administration (FDA) banned trans-fats from all food products—a move that affected additional product categories, such as fried food served at restaurants in the US (Tatusian, 2013). The subsequent use of healthier ingredients in food products was considered essential to safeguard consumers' long-term health (Tatusian, 2013).

Conceptually, ethical attributes at the brand level differ from ethical attributes at the product level in that their inclusion is a strategic means of differentiation within the product category. For example, certain brands of clothing (e.g., Patagonia) or coffee (e.g., Green Mountain Coffee) are fair trade certified, while competing brands in their respective product category are often not. In this context, it is important to recognize that differentiation based on ethical attributes may be of limited duration due to competitive imitation, as well as the introduction of industry agreements and government regulations that require that an ethical attribute be provided by all brands within a product category.

\section{Ethical Attributes and Consumer Responses to Products}

Although consumer responses to ethical attributes are often positive (Osterhus, 1997), more recent findings suggest that ethical attributes affect consumer responses negatively under certain conditions (Bodur et al., 2014, 2016; Griskevicius et al., 2007; Luchs and Kumar, 2017; 
Luchs et al., 2010; White et al., 2012). There is emerging evidence that contextual factors moderate the favorability of consumer responses to ethical attributes. Much of this evidence appears in the domain of consumer responses to products associated with ethical attributes.

At the product level, product category benefits moderate the influence of ethical attributes on product evaluations: Consumers favor ethical attributes to a greater extent in product categories in which product gentleness (versus strength) is a core benefit (Luchs et al., 2010). Relatedly, ethical attribute benefits and product category benefits jointly affect consumer responses to ethical attributes, such that consumers prefer products with ethical attributes that are congruent with product category benefits - such as utilitarian (symbolic) ethical attributes in utilitarian (symbolic) product categories (Bodur et al., 2014).

Other research shows that ethical attributes are more effective when they are offered in conjunction with hedonic rather than utilitarian products (Strahilevitz and Myers, 1998; White et al., 2012). This effect was explained in terms of congruity of the positive emotional valence of hedonic consumption and ethical attributes, which enhanced consumers' preferences for an ethical attribute pairing with hedonic products (Strahilevitz and Myers, 1998). The nature of the ethical attribute was not investigated in this context, however. Consumers are also more likely to choose products that are associated with a high level of sustainability when this choice involves a trade-off against hedonic value (i.e., aesthetic design), whereas they are less likely to choose a product with a sustainable attribute when this choice involves a trade-off against product performance (Luchs and Kumar, 2017). Again, the nature of the sustainability attribute was not examined. Overall, product-level studies regarding the impact of ethical attributes have focused on product categories and products presented without brand information, but strongly suggest that contextual factors moderate consumer responses. 


\section{Ethical Attributes and Consumer Responses to Brands}

Within a given product category, brands compete by offering diverse ethical attributes, and by choosing positions in terms of differing brand concepts. Research has thus started to examine the effects of ethical attributes on consumer responses at the brand level. Most of the brand-level investigations of ethical attribute effects have focused on how consumers respond to ethical attributes in the context of brand-level information, such as brand familiarity, brand name, or price. In the context of known versus unknown brands, Arora and Henderson (2007) found that unknown brands benefit from offering an ethical attribute in the form of cause related marketing to a greater extent than known brands. This is due to a lack of strong brand associations for unknown brands, which results in consumers placing more weight on the presence of an ethical attribute in their evaluations of unknown brands.

Subsequent research shows that consumers judge brands offering ethical attributes by considering extrinsic quality cues, including price and retailer reputation, if these brands are associated with a weak brand image (Bodur et al., 2016). If an extrinsic cue such as a higher price or a high level of retailer reputation suggests higher quality for such brands, ethical attributes enhance brand evaluations. A beneficial effect of ethical attributes does not emerge for weak image brands associated with lower quality cues, such as low price or low level of retail reputation. Brands associated with a strong brand image did not benefit from offering ethical attributes (Bodur et al., 2016). Overall, prior findings strongly suggest that the success of ethical attributes at the brand level is contingent upon contextual factors.

\section{Ethical Attribute - Brand Concept Congruity}

Brand concept is the unique meaning associated with a brand in consumers' minds (Keller, 1993; Park et al., 1986, 1991). It is based on observable brand attributes, such as price, 
quality, or design, as well as benefits consumers extract from brand use (Keller, 1993; Park et al., 1986, 1991). Brand benefits include status, self-expression, group membership, performance, and functionality (Keller 1993; Park et al., 1986, 1991; Wilcox et al., 2009). Brands are positioned in terms of symbolic or utilitarian concepts (Aaker, 1997; Bhat and Reddy, 1998; Keller, 1993). Utilitarian brands emphasize functionality and performance, whereas a symbolic brand concept seeks to meet consumers' need for self-expression and prestige (Bhat and Reddy, 1998). Differently positioned brand concepts operate within the same product category. For example, in the luggage product category, Jansport may be perceived as a utilitarian brand, because it provides good quality and high levels of functionality. Travelpro, on the other hand, may be perceived as a symbolic brand, because consumers associate this brand with experienced travelers and a sophisticated image.

Predictions regarding the effectiveness of ethical attribute types that might be offered in conjunction with different brand concepts can be based on congruity theory (Mandler, 1982; Osgood and Tannenbaum, 1955), which has been applied to multiple marketing contexts ranging from persuasion (e.g., Chandon et al., 2000; Heckler and Childers, 1992; Sujan et al., 1986; Törn and Dahlén, 2007) to product evaluations (e.g., Meyers-Levy and Tybout, 1989). Congruity theory seeks to explain the effectiveness of communication and persuasion, and posits that consumers attempt to maintain consistency among cognitive elements (Chandon et al., 2000; Eagly and Chaiken, 1993; Kamins and Gupta, 1994). In the processing of new information, individuals therefore match this information to expectations or existing cognitive schemata (Meyers-Levy and Tybout, 1989; Sujan et al., 1986). Due to their fit with existing schemata or expectations, congruent cues facilitate information processing, and therefore elicit more positive affect, positive information elaboration, and favorable consumer responses (Meyers-Levy et al., 
1994). Incongruent cues, on the other hand, require more effortful processing, as they do not match expectations or cognitive schemata, and thus give rise to more negative affect, negative information elaboration, and ultimately less favorable consumer responses (Meyers-Levy et al., 1994).

Empirical evidence indeed shows a positive effect of congruity between cognitive evaluative elements (Aggarwal and McGill, 2007; Chandon et al., 2000; Meyers-Levy et al., 1994; Meyers-Levy and Tybout, 1989). Findings regarding the effects of cue inconsistency are more equivocal, however. In the domain of product evaluations, for example, research has shown a positive impact of moderately incongruent attributes on evaluations (Meyers-Levy and Tybout, 1989). In the domain of marketing communications, several studies report a positive effect of incongruent information on attention, processing, and attitudes (Törn and Dahlén, 2008), as well as memory (Heckler and Childers, 1992; Törn and Dahlén, 2008). The need for more effortful information processing of incongruent cues increases elaboration and generates positive affect if incongruity is successfully resolved, which enhances product evaluations (Meyers-Levy et al., 1994; Meyers-Levy and Tybout, 1989). In addition, increased elaboration involved in the processing of incongruent information strengthens associations between cognitive schemas and new information and strengthens associative networks (Heckler and Childers, 1992).

In contrast to research in the persuasion, communication, and product evaluation domains, research regarding congruity effects in the domain of brand cues reports relatively robust positive effects of congruity. In the branding literature, cue consistency theory posits that multiple brand cues that convey congruent information reinforce each other, and lead to positive consequences in terms of consumer responses (Brucks et al., 2000; Miyazaki et al., 2005; Rao and Monroe, 1989). A congruity effect emerges because cue consistency reinforces the meaning 
conveyed by multiple, extrinsic brand cues such as price, brand name, warranty, or retailer information (Brucks et al., 2000; Miyazaki et al., 2005; Rao and Monroe, 1989).

For brands offering ethical attributes, congruity theory would therefore suggest that level of congruity between the brand concept and the ethical attribute matters in consumers' brand evaluations. Congruent ethical attributes and brand concepts likely result in more favorable brand evaluations because congruent ethical attributes and brand concepts reinforce each other in terms of benefits offered. In addition, congruent ethical attribute - brand concept pairings do not present a contradiction with previously held schemata or expectations regarding the brand. Incongruent ethical attribute type - brand concept pairings, on the other hand, are unlikely to enhance consumer responses, because the benefits provided by an ethical attribute in an inconsistent pairing does not add to brand benefits. The inconsistent ethical attribute is more likely to clash with consumers' previously held attitude bases regarding the benefits the brand offers. This reasoning leads to the following hypotheses:

H1: Consumers react more favorably to a utilitarian brand when the brand offers a utilitarian ethical attribute compared to a symbolic ethical attribute.

H2: Consumers react more favorably to a symbolic brand when the brand offers a symbolic ethical attribute compared to a utilitarian ethical attribute.

Congruity theory posits that an effect of ethical attribute - brand concept pairings is driven by consumers' perceptions of congruity between cognitive elements - such as the brand concept and the ethical attribute type. Congruent ethical attribute - brand concept pairings likely result in greater perceived congruity, and subsequently in more favorable brand evaluation. This mechanism has been investigated in the context of ethical attribute - product category congruity effects (Bodur et al., 2014). Due to the importance of congruity theory in deriving predictions for 
brand level effects, the proposed mediation through perceived congruity is tested to more specifically illuminate the psychological mechanisms underlying ethical attribute congruity effects as they apply to diverse brand concepts within a product category. This leads to the following process hypothesis:

H3: Perceived congruity mediates the positive effect of congruity between brand concept and ethical attribute type on consumers' brand evaluations.

\section{Conspicuousness of Brand Consumption}

Recent research suggests that consumers use ethical attributes to engage in conspicuous consumption (Griskevicius et al., 2010). Conspicuousness of brand consumption relates to the degree of visibility of brand usage to others (Graeff, 1996). Conspicuous consumption allows consumers to express their identity, status, and social standing (Braun and Wicklund, 1989), and to gain social acceptance (Rucker and Galinsky, 2009).

Two mechanisms likely influence consumer responses to ethical attribute - brand concept pairings in conspicuous brand consumption contexts. First, congruity reinforces the meaning conveyed by multiple brand cues (Brucks et al., 2000; Miyazaki et al., 2005; Rao and Monroe, 1989), and therefore results in stronger signaling potential within a consumption context. As multiple consistent cues strengthen the shared meaning conveyed by the cues, greater signaling potential of consistent ethical attribute - brand concept pairings arises. As consumers derive more signaling value from consistent ethical attribute - brand concept pairings, they are likely to evaluate ethical attribute - brand concept congruity particularly favorably when brand consumption is more conspicuous.

Second, recent research suggests that consumers use ethical attributes in conspicuous consumption contexts to engage in self-enhancement (Griskevicius et al., 2010). When 
consumers' status motives were activated, they were more likely to choose a socially responsible brand when brand choice was conspicuous, and when this choice involved a higher price.

Consumers were less likely to choose a socially responsible brand when choice was private, and when the brand was priced at a lower price point. This suggests that consumers rely on ethical brands to signal status and express their view of themselves as ethical consumers. The literature on self-concept - brand image congruity indeed suggests that congruity between self-concept and brand image leads to positive consumer responses toward brands (Dolich, 1969; Graeff, 1996; Hogg et al., 2000). To the extent that brands strengthen their brand concept by employing congruent ethical attributes, they act as a more valuable resource in expressing and enhancing consumers' self-concept. As consumers' needs for self-expression and social acceptance in conspicuous consumption settings (Braun and Wicklund, 1989; Rucker and Galinsky, 2009) are met to a greater extent by such brands, more positive evaluations should arise for consistent ethical attribute - brand concept pairings, particularly in conspicuous consumption contexts.

Taken together, these streams of literature indicate that the effects of ethical attribute brand concept congruity on brand evaluations is likely to be contingent on the level of brand consumption conspicuousness: At high levels of brand consumption conspicuousness, consistent brand cues are perceived as more effective in both signaling ethicality, and in assisting in selfenhancement. As a result, ethical attribute - brand concept congruity should lead to more favorable brand evaluations at higher levels of brand consumption conspicuousness. The effect of ethical attribute - brand concept congruity should be attenuated at lower levels of brand consumption conspicuousness.

H4: Brand evaluations are significantly more positive for congruent ethical attribute brand concept congruity pairings at high (but not low) level of brand consumption 
conspicuousness.

This article now turns to four empirical studies that document the interactive effect between brand concept and ethical attribute types on consumers' brand evaluations (Studies 1, 2, 3 , and 4), and the mediating role of perceived congruity between brand concept and ethical attribute type (Studies 2 and 3). A final study (Study 4) explores the moderating role of conspicuousness of brand consumption regarding the ethical attribute - brand concept congruity effect.

\section{Study 1: Interactive Effect of Ethical Attributes and Brand Concepts}

Study 1 examined whether congruity between ethical attribute type and brand concept influences brand evaluations (H1, H2).

\section{Method}

Study 1 used a 3 (ethical attribute: utilitarian vs. symbolic vs. control) $\times 2$ (brand concept: utilitarian vs. symbolic) $\times 2$ (product category: backpack, hoodie) mixed design with ethical attribute and brand concept as between-participants factors, and product category as within-participants factor (replicate).

Brand pretests. A pretest identified one symbolic and one utilitarian brand in the same product category that were similar in terms of brand familiarity. Participants rated a set of brands in terms of brand familiarity $(1=$ low familiarity to $9=$ high familiarity $)$ and perceived utilitarian/symbolic benefit of the brand (In your opinion, what is the main benefit of [brand]? 1 $=$ the brand is functional (i.e., is practical) to $9=$ the brand is symbolic (i.e., shows your identity)). The selection of measures was based on previous research. Measures, scale items, and sources are summarized in the appendix. The adoption of existing measures - particularly those 
used in prior research on ethical attributes - ensured appropriateness for the context as well as a satisfactory level of validation.

For evaluations of brands in the backpack product category, 42 consumers $(47.6 \%$ female, age: $21-65$ years, $M_{\text {age }}=32.76, S D=9.72$ ) were recruited on Amazon Mechanical Turk in exchange for a compensation of $\$ 1.00$. Among the brands, SwissGear was selected as the symbolic brand and Walmart's Starter as the utilitarian brand because they did not differ in brand familiarity $\left(M_{\text {Swisg }}=3.00, S D=2.60, M_{\text {Start }}=2.83, S D=2.72, p>.72\right)$. Walmart's Starter was perceived as utilitarian $\left(M_{\text {Start }}=3.48, S D=1.73\right.$, compared to scale mid-point $(4.5): t(41)=$ $3.84, p=.00)$ and more utilitarian compared to SwissGear $\left(M_{\text {Swisg }}=4.55, S D=1.73 ; t(41)=\right.$ $2.89, p<.01)$. Using the same procedure and measures, a second pretest identified a utilitarian and a symbolic brand in the hoodie product category. Thirty nine students ( $48.7 \%$ female, age: 19-35 years, $M_{\mathrm{age}}=21.72, S D=3.47$ ) were recruited in exchange for course credit. American Apparel was selected as the symbolic brand and Loblaws' Joe Fresh as the utilitarian brand because they did not differ in brand familiarity $\left(M_{A m e r}=7.87, S D=1.22, M_{J o F r}=7.49, S D=\right.$ $1.05, p>.08)$. Loblaws' Joe Fresh was perceived as utilitarian $\left(M_{J o F r}=2.90, S D=1.59\right.$; compared to scale mid-point (4.5): $t(38)=-6.31, p<.01)$ and more utilitarian than American Apparel $\left(M_{\text {Amer }}=6.39, S D=1.76 ; \mathrm{t}(37)=-8.89, p=.00\right)$. American Apparel was also perceived as symbolic (compared to scale mid-point $(4.5): t(37)=6.62, p<.01)$.

Ethical attribute pretests. In a third pretest, the participants ( $\mathrm{n}=26 ; 50 \%$ female, age: 21-53 years, $\left.M_{\text {age }}=32.27, S D=9.96\right)$ evaluated several ethical attributes based on perceived utilitarian/symbolic benefit of the ethical attribute (In your opinion, what is the main benefit of [attribute]? 1 = the attribute is functional (i.e., is practical) to $9=$ the attribute is symbolic (i.e., shows your identity)). For the backpack product category, the attribute "supports the World 
Wildlife Fund" $(M=6.23, S D=2.50)$ emerged as the symbolic ethical attribute, and "made from recycled materials" as the utilitarian ethical attribute $(M=4.19, S D=2.21 ; t(25)=3.35, p<.01)$. For the hoodie product category, the attribute "child-labor free" $(M=5.12, S D=2.78)$ emerged as the symbolic ethical attribute, and "produced with low-waste printing technology" as the utilitarian ethical attribute $(M=4.04, S D=2.09 ; t(25)=1.98, p<.10)$.

Sample and measures. Undergraduate students $(\mathrm{n}=188 ; 55.9 \%$ female, age: $18-42$ years, $M_{\text {age }}=20.98, S D=2.88$ ) participated in a computer-based study in exchange for course credit. Participants were randomly assigned to one of the six conditions with a balanced treatment group sizes (Box's $M=23.04, p=1.00$ ). They read the descriptions of a utilitarian brand (Walmart Starter backpack, Joe Fresh hoodie) or a symbolic brand (SwissGear backpack, American Apparel hoodie). The descriptions included a symbolic ("supports the World Wildlife Fund" for the backpack category, and "child labor free" for the hoodie category) or utilitarian ("made from recycled materials" for the backpack category, and "produced with low-waste printing technology" for the hoodie category) or no ethical attribute (control). To ascertain external validity of the stimuli, the prices presented with the brand information in this study $(\$ 30$ for the backpack, and $\$ 25$ for the hoodie) were determined by obtaining the average regular price of three existing brands in each product category that were readily available at different local retailers at the time of data collection. In each product category, participants provided brand evaluations on a sliding scale $(1=$ extremely unattractive to $100=$ extremely attractive $)$.

\section{Results}

A repeated-measures ANOVA with ethical attribute (utilitarian, symbolic, control) and brand concept (utilitarian, symbolic) as between-participants factors, product category (backpack and hoodie) as within-participants factor, and brand evaluation as the dependent variable 
revealed significant main effects of ethical attribute $\left(F(2,182)=4.50, p<.01\right.$, partial $\left.\eta^{2}=.05\right)$, product category $\left(F(1,182)=36.00, p=.00\right.$, partial $\left.\eta^{2}=.17\right)$, but not brand concept $(p>.1)$. There was a significant two-way interaction between brand concept and ethical attribute $(F(2$, $182)=7.53, p<.01$, partial $\eta^{2}=.08$ ), a marginally significant interaction of product category and ethical attribute $\left(F(2,182)=2.74, p<.10\right.$, partial $\left.\eta^{2}=.03\right)$, but no other significant interactions involving product category $(p>.79)$.

Further pairwise contrast with separate ANOVA for each product category shows a similar interaction pattern between brand concept and ethical attribute. For the backpack, brand evaluations improved for the utilitarian brand when it was paired with a utilitarian ethical attribute $\left(M_{U t I E A-U t B r n d}=54.43, S D=23.16\right)$, compared to a symbolic ethical attribute $\left(M_{S y m E A-}\right.$ UtlBrnd $=40.96, S D=24.65 ; F(1,117)=4.12, p<.05$, partial $\left.\eta^{2}=.03\right)$ or no ethical attribute $\left(M_{\text {NoEA-UtiBrnd }}=37.68, S D=29.05 ; F(1,124)=6.24, p<.05\right.$, partial $\left.\eta^{2}=.05\right)$. These results support hypothesis 1 . For the symbolic brand, brand evaluations improved when it was paired with a symbolic ethical attribute $\left(M_{\text {SymEA-SymBrnd }}=60.47, S D=24.31\right)$, compared to a utilitarian ethical attribute $\left(M_{U t I E A-S y m B r n d}=48.03, S D=25.19 ; F(1,117)=4.36, p<.05\right.$, partial $\left.\eta^{2}=.04\right)$ or no ethical attribute $\left(M_{\text {NoEA-SymBrnd }}=37.85, S D=26.78 ; F(1,123)=12.33, p<.01\right.$, partial $\eta^{2}=$ .09). These results support hypothesis 2 .

For the hoodie, pairing a utilitarian brand with utilitarian ethical attribute improved brand evaluations $\left(M_{U t I E A-U t B r n d}=64.29, S D=13.81\right)$ compared to a symbolic ethical attribute $\left(M_{\text {SymEA- }}\right.$ UtlBrnd $=51.92, S D=22.50 ; F(1,117)=7.15, p<.01$, partial $\left.\eta^{2}=.06\right)$, but not when compared to no ethical attribute $\left(M_{\text {NoEA-UtBrnd }}=56.76, S D=19.56 ; F(1,124)=2.58, p=.11\right.$, partial $\left.\eta^{2}=.02\right)$. Moreover, pairing symbolic brand with symbolic ethical attribute improved brand evaluation $\left(M_{\text {SymEA-SymBrnd }}=66.65, S D=12.74\right)$ compared to utilitarian ethical attribute $\left(M_{U t I E A-S y m B r n d}=\right.$ 
$58.27, S D=18.16 ; F(1,117)=4.06, p<.05$, partial $\left.\eta^{2}=.03\right)$ or no ethical attribute $\left(M_{\text {NoEA- }}\right.$

SymBrnd $=57.94, S D=20.42 ; F(1,123)=3.55, p<.10$, partial $\left.\eta^{2}=.03\right)$. Figure 1 illustrates these results.

Follow-up pairwise contrast in each product category indicates that offering an incongruent ethical attribute with brand concept is not different than not offering any ethical attribute. ANOVA results show that for the utilitarian brand, brand evaluation did not change when it was paired with a symbolic (incongruent) compared to no ethical attribute in the backpack $\left(M_{\text {SymEA-UtIBrnd }}=40.96, S D=24.65 ; M_{\text {NoEA-UtlBrnd }}=37.68, S D=29.06 ; p>.63\right)$ and hoodie category $\left(M_{\text {SymEA-UtlBrnd }}=51.92, S D=22.50 ; M_{\text {NoEA-UtlBrnd }}=56.76, S D=19.56 ; p>.05\right)$. Similarly, for the symbolic brand, brand evaluation did not change when it was paired with a utilitarian (incongruent) compared to no ethical attribute in the backpack $\left(M_{U t l E A-S y m B r n d}=48.03\right.$, $\left.S D=25.19 ; M_{N o E A-S y m B r n d}=37.85, S D=26.78 ; p>.12\right)$ and hoodie category $\left(M_{U t l E A-S y m B r n d}=\right.$ 58.27, $\left.S D=18.16 ; M_{\text {NoEA-SymBrnd }}=57.94, S D=20.42 ; p>.94\right)$.

\section{INSERT FIGURE 1 HERE}

In study 1 , congruity between ethical attribute type and brand concept significantly and consistently enhanced brand evaluations in two product categories (i.e., backpack and hoodie). For a symbolic brand, the ethical attribute increased brand evaluations when it was symbolic, but not when it was utilitarian. For a utilitarian brand, the ethical attribute enhanced brand evaluation when it was utilitarian, but not when it was symbolic. These findings are in line with congruity theory, and support $\mathrm{H} 1$ and $\mathrm{H} 2$. In addition, the results suggest that the inclusion of an ethical attribute that is incongruent with the perceived brand concept does not improve brand evaluations compared to not offering an ethical attribute. 


\section{Study 2: Mediating Role of Perceived Congruity}

Study 2 seeks to replicate the congruity effect of ethical attributes and brand concept, and explores the mediating effect of perceived congruity (H3).

\section{Method}

Study 2 used a 2 (ethical attribute: utilitarian vs. symbolic) $\times 2$ (brand concept: utilitarian vs. symbolic) $\times 2$ (product category: backpack, hoodie) mixed design with ethical attribute and brand concept as between-participants factors, and product category as within-participants factor (replicate).

Sample and measures. A sample of 180 students (52.2\% female, age: $18-51$ years, $M_{\text {age }}$ $=23.01, S D=4.59)$ participated in a computer-based study in exchange for course credit. The sample size of each treatment condition was balanced (Box's $M=16.96, p>.05$ ). The stimuli

(brands, ethical attributes, and products) were identical to those employed in study 1. Participants completed measures of brand evaluation $(1=$ extremely unappealing to $100=$ extremely appealing) and perceived brand concept - ethical attribute congruity (two items: "to what extent do you agree that .... the [attribute] reflects what the [brand] stands for/is consistent with the [brand]"; $1=$ strongly disagree to $7=$ strongly agree; $\alpha=.92$ ), which served as mediator.

\section{Results}

A repeated-measure ANOVA that included brand evaluations as the dependent variable, ethical attribute and brand concept as between-participants factors, and product category (backpack, hoodie) as within-participants factor, revealed a significant main effect of brand concept $\left(M_{U t \text { UtBrnd }}=53.19, M_{\text {SymBrnd }}=59.85 ; F(1,176)=9.94, p<.01\right.$, partial $\left.\eta^{2}=.05\right)$, but no significant main effect of ethical attribute $\left(M_{U t I E A}=56.62, M_{S y m E A}=56.43, p>.90\right)$, or 
interactions involving product category (all $p \mathrm{~s}>.80$ ). A significant two-way interaction of brand concept and ethical attribute emerged $\left(F(1,176)=16.49, p<.01\right.$, partial $\left.\eta^{2}=.09\right)$. The interaction pattern was similar for both product categories.

Brand evaluations of utilitarian brands were more favorable when the ethical attribute was utilitarian (vs. symbolic) in both the backpack $\left(M_{\text {UtIEA-UtlBrnd }}=56.07, S D=25.73 ; M_{\text {SymEA- }}\right.$ UtBrnd $=46.67, S D=20.82 ; F(1,176)=3.86, p=.05$, partial $\left.\eta^{2}=.02\right)$ and hoodie categories $\left(M_{\text {UtEA-UtBrnd }}=59.64, S D=21.38 ; M_{\text {SymEA-UtBrnd }}=50.40, S D=23.11 ; F(1,176)=4.12, p<.05\right.$, partial $\eta^{2}=.02$ ). Brand evaluations of symbolic brands were more positive when they were associated with a symbolic ethical attribute, in both the backpack (MUtEA-SymBrnd $=54.02, S D=$ $25.80 ; M_{\text {SymEA-SymBrnd }}=62.13, S D=17.51 ; F(1,176)=2.87, p<.10$, partial $\left.\eta^{2}=.02\right)$ and hoodie categories $\left(M_{U t E A-S y m B r n d}=56.73, S D=20.86 ; M_{\text {SymEA-SymBrnd }}=66.52, S D=21.03 ; F(1,176)=\right.$ 4.62, $p<.05$, partial $\eta^{2}=.03$ ). These results are consistent with hypotheses 1 and 2 .

The results at the product category level clarify the nature of the effects: For the backpack, there was a significant main effect of brand concept $(F(1,176)=3.93, p<.05$, partial $\left.\eta^{2}=.02\right)$ and a significant two-way interaction of brand concept and ethical attribute $(F(1,176)=$ $6.70, p=.01$, partial $\eta^{2}=.04$ ). Consumers evaluated the utilitarian brand more favorably when it offered a utilitarian ethical attribute $\left(M_{U t I E A-U t B r n d}=56.07, S D=25.73\right)$ versus a symbolic ethical attribute $\left(M_{\text {SymEA-UtBrnd }}=46.67, S D=20.82 ; F(1,176)=3.86, p=.05\right.$, partial $\left.\eta^{2}=.02\right)$.

Consumers evaluated the symbolic brand more favorably when it offered a symbolic ethical attribute $\left(M_{\text {SymEA-SymBrnd }}=62.13, S D=17.51\right)$ versus a utilitarian ethical attribute $\left(M_{U t I E A-S y m B r n d}=\right.$ $54.02, S D=25.80 ; F(1,176)=2.87, p<.10$, partial $\left.\eta^{2}=.02\right)$.

For the hoodie, there was a significant main effect of brand concept $(F(1,176)=4.20, p$ $<.05$, partial $\eta^{2}=.02$ ), and a significant two-way interaction of brand concept and ethical 
attribute $\left(F(1,176)=8.73, p<.01\right.$, partial $\left.\eta^{2}=.05\right)$. Consumers evaluated the utilitarian brand more favorably when it offered a utilitarian ethical attribute $\left(M_{U t l E A-U t l B r n d}=59.64, S D=21.38\right)$ versus a symbolic ethical attribute $\left(M_{\text {SymEA-UtlBrnd }}=50.40, S D=23.11 ; F(1,176)=4.12, p<.05\right.$, partial $\eta^{2}=.02$ ). Consumers evaluated the symbolic brand more favorably when it offered a symbolic ethical attribute $\left(M_{\text {SymEA-SymBrnd }}=66.52, S D=21.03\right)$ versus a utilitarian ethical attribute $\left(M_{U t l E A-S y m B r n d}=56.73, S D=20.86 ; F(1,176)=4.62, p<.05\right.$, partial $\left.\eta^{2}=.03\right)$. The results are illustrated in Figure 2.

\section{INSERT FIGURE 2 HERE}

\section{Mediating role of perceived congruity. A PROCESS model (model 8, 5,000 bootstrap} samples; Hayes, 2013) tested the conditional indirect effect of ethical attribute on brand evaluations through perceived congruity (H3). Ethical attribute served as the predictor (symbolic $=1$, utilitarian $=-1$ ), brand as the moderator ( symbolic brand $=1$, utilitarian brand $=-1$ ), perceived congruity as the mediator, and brand evaluations as the criterion.

In the backpack product category, there was a significant indirect effect of the highest order (two-way) interaction on brand evaluations (total indirect effect $=.75, S E=.47,95 \% C I$ : $[.09,1.97])$. When the brand was a utilitarian brand, the conditional indirect effect on brand evaluations was negative and significant (conditional indirect effect $=-.87, S E=.61,95 \% C I[-$ $2.69,-.07])$, suggesting that a utilitarian ethical attribute coupled with a utilitarian brand improved brand congruity and subsequent brand evaluations, as proposed in $\mathrm{H} 3$. When the brand was a symbolic brand, the indirect effect of the ethical attribute on brand evaluations was positive and marginally significant (conditional indirect effect $=.63, S E=.50,90 \% C I[.05$, 1.79]). There was a significant path coefficient for the interaction on perceived congruity $(B=$ 
$.25, t=2.63, p<.01)$, and perceived congruity had a significant effect on brand evaluations ( $B=$ $2.97, t=2.26, p<.05)$. When we included the mediator in the model, the conditional direct effect of ethical attribute on brand evaluations for utilitarian brand (conditional direct effect $=$ $3.83, S E=2.40,95 \% C I[-8.56, .90])$ and symbolic brand (conditional direct effect $=3.43, S E=$ $2.38,95 \% C I[-1.27,8.13]$ became insignificant, indicating full mediation.

In the hoodie product category, there was a significant indirect effect of the highest order (two-way) interaction on brand evaluations (total indirect effect $=1.12, S E=.66,95 \% C I[.03$, 2.61]). When the brand was a utilitarian brand, the conditional indirect effect on brand evaluations was negative and significant (conditional indirect effect $=-1.04, S E=.68,95 \% C I[-$ $2.77,-.06])$, suggesting that a utilitarian ethical attribute coupled with a utilitarian brand improved brand congruity and subsequent brand evaluations. When the brand was a symbolic brand, the indirect effect of the ethical attribute on brand evaluations was positive and significant (conditional indirect effect $=1.19, S E=.75,95 \% C I[.05,3.08]$ ). There was a significant path coefficient for the interaction on perceived congruity $(B=.37, t=4.52, p=.00)$, and perceived congruity had a significant association with brand evaluations $(B=3.03, t=2.05, p<.05)$. The conditional direct effect of ethical attribute on brand evaluations for utilitarian brand (conditional direct effect $=-3.58, S E=2.31,95 \% C I[-8.15, .99])$ and symbolic brand (conditional direct effect $=3.71, S E=2.33,95 \% C I[-.89,8.31]$ were not significant.

Study 2 replicated findings of study 1 and showed that the impact of an ethical attribute on brand evaluations is contingent upon the level of congruity between brand concept and ethical attribute type (i.e., symbolic vs. utilitarian). This supports $\mathrm{H} 1$ and H2. Moreover, perceived congruity mediated the positive effect of congruity between ethical attribute and brand concept (H3). 


\section{Study 3: Replication with Different Product Category and Brands}

In order to increase the generalizability of previous findings, study 3 tested the ethical attribute - brand concept interaction, as well as the mediating role of perceived congruity in a new product category. Whereas studies 1 and 2 included private-label brands, study 3 involved a set of national brands in order to rule out the potential confounding of retailer and brand perceptions on consumers' brand evaluations.

\section{Method}

A sample of 242 MTurk panel members (53.7\% female, age: $18-69$ years, $M_{\text {age }}=35.93$, $S D=11.75$ ) participated in a computer-based study in exchange for $\$ 1.00$. Study 3 used a 3 (ethical attribute: utilitarian vs. symbolic vs. control) $\times 2$ (brand concept: utilitarian vs. symbolic) between-participants design in the carry-on luggage product category. The procedure, ethical attribute stimuli, and measures were adopted from study 2 . Brand evaluation served as the dependent variable $(1=$ extremely unappealing to $100=$ extremely appealing $)$.

Brand pretests. A pretest identified one symbolic and one utilitarian brand in the carry-on luggage category. Participants rated a set of brands in terms of perceived utilitarian/symbolic benefit of the brand (In your opinion, what is the main benefit of [brand]? 1 = the brand is functional (i.e., is practical) to $9=$ the brand is symbolic (i.e., shows your identity). In total, 47 students ( $48.9 \%$ female, age: $17-30$ years, $\left.M_{\text {age }}=21.40, S D=2.13\right)$ were recruited in exchange for course credit. TravelPro emerged as the symbolic brand, and Jansport as the utilitarian brand; Jansport was perceived as somewhat utilitarian $\left(M_{\text {Jansp }}=3.94, S D=2.04\right.$; compared to scale 
mid-point (4.5): $t(46)=-1.90, p<.10)$, and marginally more utilitarian than TravelPro $\left(M_{T r v l P}=\right.$ $4.47, S D=1.25 ; t(41)=-1.78, p<.10)$.

\section{Results}

An ANOVA with ethical attribute (including control condition) and brand concept as between-participants factors, and brand evaluation as the dependent variable revealed a significant interaction effect of ethical attribute and brand concept $(F(2,236)=5.64, p<.01$, partial $\left.\eta^{2}=.05\right)$. Brand evaluations of the utilitarian brand were more positive when it was paired with a utilitarian, compared to a symbolic or no ethical attribute $\left(M_{U t I E A-U t B r n d}=70.80, S D=\right.$ 16.29; $M_{\text {SymEA-UtBrnd }}=57.09, S D=21.46 ; M_{\text {NoEA-UtBrnd }}=60.96, S D=24.66 ; F(2,236)=3.83, p<$ .05 , partial $\eta^{2}=.03$ ). These results support H1. Brand evaluations of the symbolic brand benefited from inclusion of a symbolic ethical attribute, compared to a utilitarian or no ethical attribute $\left(M_{\text {SymEA-SymBrnd }}=72.83, S D=14.03 ; M_{U t I E A-S y m B r n d}=62.20, S D=21.58 ; M_{\text {NoEA-SymBrnd }}=\right.$ 64.49, $S D=24.58 ; F(2,236)=2.51, p<.10$, partial $\left.\eta^{2}=.02\right)$. These results support H2. Figure 3 illustrates this interaction.

Pairwise ANOVA contrasts show that brand evaluations improved for the utilitarian brand when it was paired with a utilitarian ethical attribute $\left(M_{U t I E A-U t B r n d}=70.80, S D=16.29\right)$, compared to a symbolic ethical attribute $\left(M_{\text {SymEA-UtlBrnd }}=57.09, S D=21.46 ; F(1,135)=9.27, p\right.$ $<.05$, partial $\left.\eta^{2}=.06\right)$ or no ethical attribute $\left(M_{\text {NoEA-UtBrnd }}=60.96, S D=24.66 ; F(1,169)=3.98\right.$, $p<.05$, partial $\eta^{2}=.02$ ). For the symbolic brand, brand evaluations improved when it was paired with a symbolic ethical attribute $\left(M_{\text {SymEA-SymBrnd }}=72.83, S D=14.03\right)$, compared to a utilitarian ethical attribute $\left(M_{S y m E A-S y m B r n d}=62.20, S D=21.58 ; F(1,135)=5.83, p<.05\right.$, partial $\left.\eta^{2}=.04\right)$ or no ethical attribute $\left(M_{\text {NoEA-SymBrnd }}=64.49, S D=24.58 ; F(1,168)=2.98, p<.10\right.$, partial $\left.\eta^{2}=.02\right)$.

Further analyses indicate that an ethical attribute incongruent with the brand concept does 
not enhance brand evaluations, as compared to not offering any ethical attribute. ANOVA results show that for the utilitarian brand, brand evaluation did not change when it was paired with a symbolic (incongruent) attribute compared to no ethical attribute $\left(M_{\text {SymEA-UtlBrnd }}=57.09, S D=\right.$ 21.46; $\left.M_{\text {NoEA-UtIBrnd }}=60.96, S D=24.66 ; p>.44\right)$. Similarly, for the symbolic brand, brand evaluation did not change when it was paired with utilitarian (incongruent) attribute compared to no ethical attribute $\left(M_{U t I E A-S y m B r n d}=62.20, S D=21.58 ; M_{\text {NoEA-SymBrnd }}=64.49, S D=24.58 ; p>\right.$ $.64)$.

\section{INSERT FIGURE 3 HERE}

Mediating role of perceived congruity. Consistent with the findings of study 2 , perceived congruity mediated the interaction effect of ethical attribute and brand concept on brand evaluations. Specifically, the PROCESS analysis (model 8, 5,000 bootstrap samples; Hayes, 2013) showed a significant indirect effect of the highest order (two-way) interaction (total indirect effect $=1.15, S E=.73,95 \% C I[.11,3.07])$. When the brand was utilitarian, there was a marginally significant and negative indirect effect through perceived congruity (conditional indirect effect $=-1.13, S E=.93,90 \% C I[-3.30,-.05])$. When the brand was symbolic, there was a significant and positive indirect effect (conditional indirect effect $=1.17, S E=.85,95 \% C I$ $[.02,3.43])$. There was a significant path coefficient for the interaction on perceived congruity $(B$ $=.27, t=2.50, p<.05)$, and perceived congruity had a significant path coefficient with regard to brand evaluation $(B=4.94, t=3.19, p<.05)$. With the mediator included in the model, the conditional direct effect of ethical attribute on brand evaluations for the utilitarian brand remained significant (conditional direct effect $=-5.73, S E=2.18,95 \% C I[-10.05,-1.41]$ ), but for symbolic brand the conditional direct effect became insignificant (conditional direct effect $=$ 
4.15, $S E=2.14,95 \% C I[-.08,8.38]$, indicating full mediation.

Study 3 extended the findings of studies 1 and 2 to a new product category and a new set of national brands. It showed that the impact of an ethical attribute on brand evaluation depends on the congruent pairing of ethical attribute and brand concept type. This supports $\mathrm{H} 1$ and $\mathrm{H} 2$. Moreover, study 3 showed that consumers' perceptions of congruity plays a mediating role in the positive effect of congruity between ethical attribute and brand concept (H3). The partial mediation observed for the utilitarian brand of carry-on luggage is inconsistent with the full mediation for the utilitarian brand in the backpack and hoodie product categories in study 2 . This may point to a role of product category in influencing ethical attribute - brand concept congruity effects.

\section{Study 4: The Moderating Role of Brand Usage Conspicuousness}

The results of studies 1, 2, and 3 suggest that ethical attribute - brand concept congruity positively influences consumers' brand evaluations. Brand consumption in the product categories tested in studies 1, 2, and 3 (hoodies, backpack, and carry-on luggage) are relatively conspicuous. Study 4 examines whether the observed effects of ethical attribute - brand concept congruity emerge at high (but not low) levels of conspicuousness of brand consumption (H4).

\section{Method}

Study 4 employed a 2 (ethical attribute: utilitarian vs. symbolic) $\times 2$ (brand concept: utilitarian vs. symbolic) between-participants design, in which perceived conspicuousness of brand consumption was a measured variable.

Ethical attribute pretests. Based on the pretest to study 1, the attribute "supports the Free the Children Foundation" $(M=5.77, S D=2.21)$ was chosen as a symbolic ethical attribute, and 
"made with eco-friendly materials" $(M=3.77, S D=1.73 ; t(25)=3.64, p=.001)$ as the utilitarian ethical attribute.

Brand pretests. The brand selection in Study 4 was based on the pretest to study 3 in which participants also rated a set of brands of sport socks in terms of perceived utilitarian/symbolic brand concept (In your opinion, what is the main benefit of [brand]? $1=$ the brand is functional (i.e., is practical) to $9=$ the brand is symbolic (i.e., shows your identity). Diesel was selected as the symbolic brand, and George (a Walmart private-label brand) as the utilitarian brand. Walmart's George brand was perceived as utilitarian $\left(M_{\text {Gorg }}=3.34, S D=1.66\right.$; compared to scale mid-point (4.5): $t(46)=-4.79, p=.00)$, and as significantly more utilitarian than Diesel $\left(M_{\text {Diesel }}=6.30, S D=2.13 ; t(46)=-7.27, p=.00\right)$.

Sample and measures. Undergraduate students $(\mathrm{n}=104 ; 49 \%$ female, age: $18-36$ years, $\left.M_{\text {age }}=21.2, S D=2.54\right)$ participated in a computer-based study in exchange for course credit. Participants provided brand evaluations (three items: $1=$ unfavorable/bad/negative to $7=$ favorable/good/positive; $\alpha=.94$ ) and completed a measure of perceived conspicuousness of brand consumption (four items: $1=$ visible/noticeable/conspicuous/public to $7=$ nonvisible/unnoticeable/inconspicuous/private; $\alpha=.79$ ).

\section{Results}

An ANOVA with brand evaluation as the dependent variable, and ethical attribute and brand concept as the independent variables showed a significant interaction effect of ethical attribute and brand concept $\left(F(1,103)=11.03, p<.01\right.$, partial $\left.\eta^{2}=.10\right)$. Consistent with H1, evaluations of the utilitarian brand improved when it was paired with a utilitarian ethical attribute $\left(M_{\text {UtlEA-UtlBrnd }}=4.71, S D=1.11 ; M_{\text {SymEA-UtlBrnd }}=3.80, S D=1.33 ; F(1,100)=7.64, p<.01\right.$, partial $\left.\eta^{2}=.07\right)$. Evaluations of the symbolic brand were more positive when the brand provided an 
ethical attribute that was symbolic $\left(M_{U t I E A-S y m B r n d}=4.51, S D=1.25 ; M_{\text {SymEA-SymBrnd }}=5.17, S D=\right.$ $1.16 ; F(1,100)=3.79, p=.05$, partial $\left.\eta^{2}=.04\right)$, in support of $\mathrm{H} 2$. Figure 4 illustrates this interaction.

\section{INSERT FIGURE 4 HERE}

The moderating role of conspicuousness in the evaluation of ethical attribute-brand concept pairings was tested in a PROCESS model (model 3, 5,000 bootstrap samples; Hayes, 2013). Ethical attribute, brand concept, and perceived conspicuousness served as predictors, and brand evaluation as criterion. A significant interaction of ethical attribute, brand concept, and conspicuousness of brand consumption emerged $(B=.19, S E=.085, t=2.22, p<.05)$. The interaction pattern (Figure 5) suggests that the positive congruity effect between brand concept and ethical attribute only emerges at higher levels of conspicuousness $(+1 \mathrm{SD}=5.25)(B=+.65$, $S E=.16, t=3.96, p=.0001)$. At lower levels of conspicuousness $(-1 \mathrm{SD}=2.42)$, there was no effect of congruity between ethical attribute and brand concept on brand evaluation ( $B=+.12, S E$ $=.17, p>.50$ ). Johnson-Neyman results suggest that the positive effect of congruity between ethical attribute and brand concept was significant for conspicuousness scores above 3.17.

\section{INSERT FIGURE 5 HERE}

This study supports $\mathrm{H} 4$ by demonstrating that conspicuousness of brand consumption moderates the congruity effect of ethical attributes and brand concept on brand evaluations. The presence of a symbolic (utilitarian) ethical attribute increased evaluations of a symbolic (utilitarian) brand when brand consumption was perceived to be conspicuous. When consumers 
perceived brand consumption to be at low levels of conspicuousness, a significant and positive ethical attribute - brand concept congruity effect did not arise.

This finding points toward additional benefits consumers derive from adopting brands offering ethical attributes: When the adoption of ethical attributes that support a brand concept can be observed by others, consumers may derive signaling and self-enhancement benefits from supporting a brand offering ethical attributes. This mechanism potentially drives more positive brand evaluations, but only if ethical attributes and brand concepts are congruent. This suggests that consumers respond to the consistency of ethical attribute and brand concept cues, but also to additional benefits from having others observed their usage of brands offering ethical attributes. In contexts in which consumers perceive brand consumption to be relatively high in conspicuousness, brands thus stand to gain by offering ethical attributes that are congruent with the brand concept.

\section{Conclusion and Implications}

In light of the increasing adoption of ethical attributes by brands, this research explored what ethical attribute types are most likely to increase consumers' evaluations of symbolic or utilitarian brands. It examined whether brands competing within the same product category and associated with differentiated brand concepts might benefit from offering different types of ethical attributes.

Building on congruity theory, four studies use real brands to investigate the interactive effect of symbolic/utilitarian brand concepts and symbolic/utilitarian ethical attributes on consumers' brand evaluations. Study 1 demonstrates that congruity between ethical attributes and brand concepts enhances brand evaluations, compared to incongruent brand concept - 
ethical attribute pairings. Study 2 replicates these findings and demonstrates that the positive (negative) effect of the (in)congruity between brand concept and ethical attributes is mediated by consumers' perceptions of congruity. Study 3 generalizes these findings to a different product category and set of brands. Study 4 shows that a significant effect of ethical attribute - brand concept congruity emerges only when the brand consumption is perceived to be conspicuous. Finally, studies 1 and 3 indicate that offering incongruent ethical attributes do not yield improvements in brand evaluations compared to offering no ethical attribute at all.

This article makes several contributions to the ethical attribute and the brand concept literature: First, it theoretically grounds a discussion of the effect of ethical attributes paired with differing brand concepts in congruity theory. Whereas prior research at the product level has proposed congruity effects (Bodur et al., 2014), conceptual development with regard to brand concepts has been lacking. The ethical attribute - brand concept congruity framework proposed here is strongly supported by the empirical findings of the current research.

A second contribution of this article is the empirical test of ethical attribute - brand concept congruity effects in multiple studies involving different brands in various product categories. In the context of ethical attribute - brand concept pairings, congruity effects emerge consistently across studies. Although recent research demonstrates that ethical attributes do not elicit unequivocally positive consumer responses toward brands (Arora and Henderson, 2007; Bodur et al., 2016), the current set of studies supports a robust, positive response to ethical attributes that match a brand's concept. In addition, prior research documented ethical attribute congruity effects at the product level (Bodur et al., 2014), but has also found that product level congruity findings do not necessarily hold at the brand level (LeBoeuf and Simmons, 2010). In finding consistent support for positive ethical attribute - brand concept congruity effects, the 
current research indicates that congruity effects observed in the ethical attribute context seem more robust than those reported in the domain of persuasive appeals (Bodur and Grohmann, 2004; LeBoeuf and Simmons, 2010).

Third, this research also found a mediating role of consumers' congruity perceptions, and thereby identifies the process underlying the interaction effect of ethical attributes and brand concepts. This finding lends additional support to the explanatory power of congruity theory in the context of ethical attributes paired with various brand concepts. Finally, this research also identifies conspicuousness as a moderator of the ethical attribute - brand concept congruity effect, and suggests that congruity matters particularly when conspicuousness is high. This finding adds to the current understanding of the contexts in which congruity effects are strengthened, and could guide managers in selecting the most promising contexts for the introduction of ethical attributes to be offered by their brands.

\section{Theoretical Implications}

The majority of articles in the corporate social responsibility and ethical attribute literature focus on symbolic ethical attributes (Arora and Henderson, 2007; Folse et al., 2010; Hagtvedt and Patrick, 2016; Lafferty et al., 2004; Winterich and Barone, 2011). The current research builds on emerging evidence that symbolic and utilitarian ethical attributes may have differential effects on consumer responses (Bodur et al., 2014), and supports the notion that utilitarian ethical attributes can elicit favorable consumer responses under certain conditions, such as when ethical attributes and brand concepts are congruent.

The observation that the type of ethical attribute matters in consumers' evaluations of brands representing different brand concepts also raises the question whether a lack of congruity between corporate social responsibility information and brand values explains the null effect of 
corporate social responsibility information reported in earlier research (Torelli et al., 2012).

Specifically, prior research that investigated self-enhancement, openness, and conservation as brand values did not find evidence for a positive effect of corporate social responsibility information associated with brands representing openness or conservation values compared to a control condition (Torelli et al., 2012). Corporate social responsibility information also lowered the favorability of responses to brands representing self-enhancement values (Torelli et al., 2012), presumably due to the motivational conflict between corporate social responsibility induced self-transcendence (i.e., concerns regarding the welfare of others or the environment) and brand positioning related self-enhancement goals (i.e., dominance over people and resources) (Torelli et al., 2012). Based on the current findings, it is possible that a positive effect of CSR information on brands associated with a conservation concept may have emerged for different, more congruent corporate social responsibility activities.

Although this speculation opens avenues for future research in the corporate social responsibility and brand concept domain, it is also important to note that the current article differs from earlier research in important ways. These differences pertain to the nature of brand concepts that were investigated, and the focus on ethical brand attributes. Whereas previous research examined brands with openness, conservation, and self-enhancement brand values (Torelli et al., 2012), the current work is based on the symbolic/utilitarian brand concept distinction that has been proposed in previous literature (Aaker, 1997; Bhat and Reddy, 1998; Keller, 1993). Moreover, the current research focuses on brand-level ethical attributes rather than more global corporate social responsibility, which refers to firm-level activities that relate to the fulfillment of societal obligations (Torelli et al., 2012). The current article conceptually and empirically distinguishes utilitarian and symbolic ethical attributes, whereas prior work (Torelli 
et al., 2012) did not investigate the role of the nature of corporate social responsibility information. The current article thus presents a complementary, novel perspective in terms of the interactive effect of brand concepts and the ethical attribute types on consumers' brand evaluations.

This research also complements inquiries into the contextual factors influencing ethical attributes offered by brands (Arora and Henderson, 2007; Bodur et al., 2016). This article focused on the moderating role of conspicuousness of consumption in the evaluation of brands providing congruent ethical attributes. It shows that the positive effect of congruity between ethical attribute and brand concept emerges particularly strongly when consumers perceive their brand consumption to be conspicuous. This finding points to the possibility that consumers' brand evaluations are driven from the reinforcement of brand concept benefits offered by a congruent ethical attribute, as well as an additional social benefit from the consumption of brands offering consistent benefits when others can observe their brand consumption. In this research, the role of conspicuousness of brand consumption was investigated to examine boundaries to the effectiveness of congruent ethical attribute - brand concept pairings. Given that conspicuousness of brand consumption indeed affected consumers' brand evaluations, future research might be directed at a broader set of questions regarding the motivating role of conspicuousness of consumption when it comes to the evaluation and adoption of ethical attributes.

\section{Managerial Implications}

There are several managerial implications arising from the findings of this research. First, in order to elicit positive consumer responses to a brand's introduction of an ethical attribute, it is critical to consider the congruity between the nature of the ethical attribute and the brand 
concept. The offering of utilitarian ethical attributes, such as low-waste technology, recycled or environmentally friendly materials, is most beneficial for brands associated with a utilitarian brand concept. Symbolic ethical attributes, such as advocacy concerning child labor, support of environmental conservation groups, or support of causes involving children's health and wellbeing, evoke more positive consumer responses when they are offered by symbolic brands. This research considered a variety of utilitarian and symbolic ethical attributes, and a range of brands representing utilitarian and symbolic brand concepts in different product categories. Across studies, ethical attribute - brand concept congruity effects emerged, regardless of the specific attributes or brands considered. This suggests that practitioners can select among several possible utilitarian and symbolic ethical attribute alternatives and elicit positive evaluations—as long as these attributes have a high level of fit with the brand concept they are paired with. This ability to choose among utilitarian or symbolic ethical attribute alternatives allows managers to consider ethical attributes that facilitate differentiation from competing brands in terms of the ethical attributes offered.

Secondly, studies 1 and 3 show that the addition of an ethical attribute that is incongruent with the brand concept does not result in more positive consumer responses to the brand than the absence of an ethical attribute. This suggests that introduction of an incongruent ethical attribute may constitute an investment of resources that does not lead to favorable market outcomes. Pepsi Co.'s adoption of healthy ingredients for new, highly symbolic soft drink brand (Aaker, 1997) may thus not have been an optimal choice.

Finally, it is noteworthy that an ethical attribute - brand concept congruity strategy is more effective for brands that are associated with higher levels of brand consumption conspicuousness. For example, in the wrist watch product category that is associated with 
relatively high levels of brand consumption conspicuousness, it would be beneficial for a brand with a utilitarian brand concept (e.g., Timex) to offer a utilitarian ethical attribute (e.g. rechargeable batteries, use of environmentally friendly mined or recycled metals for wrist bands), whereas a brand with a symbolic brand concept (e.g., Swatch) would likely benefit from selecting symbolic ethical attribute (e.g., cause marketing, community involvement). In other words, the selection of ethical attributes in line with the brand concept is particularly important in the context of brands that are consumed conspicuously.

\section{Limitations and Future Research Directions}

This research relied on existing brands to test the hypotheses in order to increase the external validity of this research. Care was taken to identify appropriate brands across in different product categories in several pretests. Brand selection required that the brands be similar in familiarity, as prior research indicated that brand familiarity plays a significant role in the evaluation of brands offering ethical attributes (Arora and Henderson, 2007). At the same time, the selected brands had to differ in consumers' perceptions of the symbolic versus utilitarian nature of their brand concepts. This selection process gives rise to several limitations: First, although the brands chosen were identified based on similar familiarity scores and clearly identified utilitarian or symbolic brand concepts, there are multiple factors this research did not control for and that might have an influence on consumers' evaluation of brand pairings with ethical attributes. These include price, prior history of ethical attribute adoption, or innovativeness associated with the brands included in this research—all of which may have contributed to consumers' observed brand evaluations.

Second, from a methodological standpoint, a limitation of this research pertains to the use of single-item scales for many of the constructs, such as utilitarian and symbolic brand concepts. 
The scales were selected from publications in the ethical attribute domain, previously validated, and context appropriate. The use of existing scales also facilitates the discussion of the current findings against results reported in the product domain. It is nonetheless important to acknowledge that use of multi-item scales in the measurement of latent constructs would have been preferable and is strongly recommended in future research.

With regard to the measurement of symbolic versus utilitarian brand concepts, it is also critical to point out that this research operationalized brand concepts along a one-dimensional continuum. This operationalization allowed for the empirical test of the congruity between brand concepts and ethical attributes — which have been conceptualized in terms of a utilitarian symbolic continuum in prior literature on ethical attribute effects (Bodur et al., 2014). The branding literature suggests, however, that brand concepts are located within a two-dimensional utilitarian/symbolic space (Bhat and Reddy, 1998). We therefore acknowledge that the findings here are based on a consideration of a limited set of brand concepts, namely those characterized by a high utilitarian/low symbolic and high symbolic/low utilitarian positioning. The current research does therefore not speak to the effectiveness of ethical attribute choice of brands that are highly utilitarian and highly symbolic. Further empirical evidence would be needed to address this issue.

Third, the brand selection process based on familiarity and brand concepts resulted in a set of brands in product categories that could be considered relatively utilitarian (i.e., sports socks, hoodies, backpacks, carry-on luggage). Even though brand consumption in these categories is relatively conspicuous, the product categories are nonetheless associated with a relatively high consumer need for functionality. This includes warmth for hoodies, sturdiness for backpacks and carry-on luggage, or cushioning and sweat wicking properties for sports socks. 
This may relate to the generally smaller mean differences that manifested for the symbolic (as opposed to the utilitarian) brands across studies. Specifically, marginally significant differences emerged for the symbolic hoodie brand in Study 1 (symbolic ethical attribute compared to control: $M_{\text {SymBrnd-SymEA }}=66.65, S D=12.74 ; M_{\text {SymBrnd-NoEA }}=57.94, S D=20.42 ; F(1$, $123)=3.55, p=.06$, partial $\eta^{2}=.03$ ), the symbolic backpack brand in Study 2 (symbolic compared to utilitarian ethical attribute: $M_{\text {SymBrnd-SymEA }}=62.13, S D=17.51 ; M_{\text {SymBrnd-UtIEA }}=$ $54.02, S D=25.80 ; F(1,176)=2.87, p=.09$, partial $\left.\eta^{2}=.02\right)$, and the symbolic carry-on luggage brand in Study 3 (symbolic ethical attribute compared to control: $M_{S y m B r n d-S y m E A}=72.83, S D=$ $14.03 ; M_{\text {SymBrnd-NoEA }}=64.49, S D=24.58 ; F(1,168)=2.98, p=.09$, partial $\left.\eta^{2}=.02\right)$, whereas all other mean differences involving symbolic brand concepts were statistically significant.

Differences in magnitude were also observed for the mediating effects of perceived congruity across studies 2 and 3 . In study 2 , perceived congruity fully mediated the effect of ethical attribute - brand concept congruity, while a partial mediation emerged for the utilitarian ethical attribute - brand concept pairing in study 3 , which applied a different product category. By considering the impact of product category related factors — such as the utilitarian or symbolic nature of the product category — on the effects of ethical attribute - brand concept congruity, future investigations might be able to shed further light on the marginally significant results of the presence of symbolic brand concept or the comparison with utilitarian brand concept, and full versus partial mediation through perceived congruity across different product categories. The nature of the product categories included in this research precluded a first exploration of the relative role of the possible three-way interaction of ethical attribute types, brand concepts, and product category benefits. Considering prior research (Bodur et al., 2014), product category benefits should influence consumers' evaluations of ethical attribute 
presence - as do the brand concepts investigated in this research. Of interest is therefore to what extent both product category and brand concept match may jointly drive consumer evaluations of brands offering utilitarian or symbolic ethical attributes.

In addition, it is important to note that to ascertain external validity and rule out a cofounding effect of price, identical prices were presented for the utilitarian and symbolic brands in each product category. It is likely, however, that price information plays an important role in consumers' responses to ethical attributes offered by brands representing utilitarian and symbolic brand concepts. In fact, research suggest that higher price levels affect brand concept perceptions (Keller, 1993; Park et al., 1986, 1991), such that lower (higher) prices are often associated with utilitarian (symbolic) brand concepts. Further research is therefore needed to provide more insight regarding the effect of price information when brands representing different brand concepts offer ethical attributes. The present research nonetheless provides a starting point for future investigations of the role of ethical attribute types and their potential interactions with price with regard to consumers' evaluations of brands representing symbolic and utilitarian brand concepts.

Finally, it is important to acknowledge that this research used random assignment to experimental conditions within experiments, whereas participants were purposively sampled from existing cohorts of undergraduate students and consumer panels. As a result, sampling was not completely randomized. Although such an approach is common in experimental research, it has implications for statistical inferences that can be drawn on the basis of this research. The findings of this research may nonetheless be useful in guiding future inquiries on the impact of ethical attributes on consumer responses to brands. 
Compliance with Ethical Standards:

All procedures performed in studies involving human participants were in accordance with the ethical standards of the institutional and/or national research committee and with the 1964

Helsinki declaration and its later amendments or comparable ethical standards. Informed consent was obtained from all individual participants included in the study. 


\section{References}

Aaker, J. L. (1997), “Dimensions of brand personality”, Journal of Marketing Research, Vol. 34 No. 3, pp. 347-356.

Aggarwal, P. and McGill, A. L. (2007), "Is that car smiling at me? Schema congruity as a basis for evaluating anthropomorphic products", Journal of Consumer Research, Vol. No., pp. .

Arora, N., and Henderson, T. (2007), "Embedded premium promotion: Why it works and how to make it more effective", Marketing Science, Vol. 26 No. 4, pp. 514-531.

Banister, E. N., and Hogg, M. K. (2004), “Negative symbolic consumption and consumers' drive for self-esteem: the case of the fashion industry", European Journal of Marketing, Vol. 38 No. 7 , pp. $850-868$.

Bhat, S. and Reddy, S. K. (1998), "Symbolic and functional positioning of brands," Journal of Consumer Marketing, Vol. 15 No. 1, pp. 32 - 43.

Bodur, H. O., Gao, T., and Grohmann, B. (2014), “The ethical attribute stigma: Understanding when ethical attributes improve consumer responses to product evaluations", Journal of Business Ethics, Vol. 122 No. 1, pp. 167-177.

Bodur, H. O., and Grohmann, B. (2004), “Goal-oriented ad design: An investigation of message type and consumption goal congruence", in Boctor, F. F., and Martel, A. (Eds.), Administrative Sciences Association of Canada (ASAC) Conference Proceedings, Vol. 25, Administrative Sciences Association of Canada, Quebec City (Canada), pp. 1 - 8 .

Bodur, H. O., Tofighi, M., and Grohmann, B. (2016), "When should private label brands endorse ethical attributes?", Journal of Retailing, Vol. 92 No. 2, pp. 204-217.

Braun, O. L., and Wicklund, R. A. (1989), "Psychological antecedents of conspicuous consumption", Journal of Economic Psychology, Vol. 10 No.2, pp. 161-187. 
Brucks, M., Zeithaml, V. A., and Naylor, G. (2000), "Price and brand name as indicators of quality dimensions for consumer durables", Journal of the Academy of Marketing Science, Vol. 28 No. 3, pp. 359-74.

Chandon, P., Wansink, B., and Laurent, G. (2000), “A benefit congruency framework of sales promotion effectiveness", Journal of Marketing, Vol. 64 No. 4, pp. 65-81.

Chatterji, A. (2013), "When corporations fail at doing good", available at: http://www.newyorker.com/business/currency/when-corporations-fail-at-doing-good (accessed July 13 2017).

Dolich, I. (1969), "Congruence relationships between self-images and product brands", Journal or Marketing Research, Vol. 6 No. 1, pp. 80-84.

Eagly, A. H., and Chaiken, S. (1993), The Psychology of Attitudes, Harcourt Brace Jovanovich College Publishers. Fort Worth, TX.

Folse, J. A., Niedrich, R. W., and Grau, S. L. (2010), "Cause-relating marketing: The effects of purchase quantity and firm donation amount on consumer inferences and participation intentions", Journal of Retailing, Vol. 86 No. 4, pp. 295-309.

Graeff, T. (1996), "Image congruence effects on product evaluations: The role of self-monitoring and public/private consumption", Psychology and Marketing, Vol. 13 No. 5, pp. 481499.

Griskevicius, V., Tybur, J. M., Sundie, J. M., Cialdini, R. B., Miller, G. F., and Kenrick, D. T. (2007), "Blatant benevolence and conspicuous consumption: When romantic motives elicit strategic costly signals", Journal of Personality and Social Psychology, Vol. 93 No. 1, pp. $85-102$. 
Griskevicius, V., Tybur, J. M., and Van den Bergh, B. (2010), "Going green to be seen: Status, reputation, and conspicuous conservation", Journal of Personality and Social Psychology, Vol. 98 No. 3, pp. 392-404.

Hagtvedt, H., and Patrick, V. M. (2016), "Gilt and guilt: Should luxury and charity partner at the point of sale?", Journal of Retailing, Vol. 92 No. 1, pp. 56-64.

Hallock, B. (2013), "Rise and fall of trans fat: A history of partially hydrogenated oil", available at: http://www.latimes.com/food/dailydish/la-dd-rise-and-fall-of-trans-fat-20131107story.html (accessed October 16 2018).

Hogg, M. K., Cox, A. J., and Keeling, K. (2000), “The impact of self-monitoring on image congruence and product/brand evaluation", European Journal of Marketing, Vol. 34 No. 5/6, pp. 641-667.

Hayes, Andrew F. (2013), Introduction to Mediation, Moderation, and Conditional Process Analysis: A Regression-based Approach, Guilford Press, New York.

Heckler, S. E., and Childers, T. L. (1992), "The role of expectancy and relevancy in memory for verbal and visual information: What is incongruency?", Journal of Consumer Research, Vol. 18 No. 2, pp. 475-492.

Kamins, M. A., and Gupta, K. (1994), “Congruence between spokesperson and product type: A matchup hypothesis perspective", Psychology and Marketing, Vol. 11 No. 6, pp. 569586.

Keller, K. L. (1993), “Conceptualizing, measuring, and managing customer-based brand equity”, The Journal of Marketing, Vol. 57 No. 1, pp. 1-22. 
Lafferty, B. A., Goldsmith, R. E., and Hult, G. T. M. (2004), "The impact of the alliance on the partners: A look at cause-brand alliances”, Psychology and Marketing, Vol. 21 No. 7, pp. $509-531$.

LeBoeuf, R. A., and Simmons, J. P. (2010), "Branding alters attitude functions and reduces the advantage of function-matching appeals", Journal of Marketing Research, Vol. 47 No. 2, pp. 348-360.

Levy, S. J. (1959), "Symbols for sale”, Harvard Business Review, Vol. 37 No. July-August, pp. $117-124$.

Luchs, M. G., and Kumar, M. (2017), "Yes, but this other one looks better/works better: How do consumers respond to trade-offs between sustainability and other valued attributes?", Journal of Business Ethics, Vol. 140 No. 3, pp. 567-584.

Luchs, M. G., Naylor, R. W., Irwin, J. R., and Raghunathan, R. (2010), “The sustainability liability: Potential negative effects of ethicality on product preference", Journal of Marketing, Vol. 74 No. 5, pp. 18-31.

Mandler, G. (1982), “The structure of value: Accounting for taste”, in Clark, M. S. and Fiske, S. T. (Eds.), Affect and cognition: The $17^{\text {th }}$ annual Carnegie symposium, Hillsdale, NJ, Erlbaum, pp. 3-36.

Meyers-Levy, J., Louie, T. A., and Curren, M. T. (1994), "How does the congruity of brand names affect evaluations of brand name extensions?", Journal of Applied Psychology, Vol. 79 No. 1, pp. 46-53.

Meyers-Levy, J., and Tybout, A. M. (1989), "Schema congruity as a basis for product evaluation", Journal of Consumer Research, Vol. 16 No. 1, pp. 39-54. 
Miyazaki, A. D., Grewal, D., and Goodstein, R. C. (2005), "The effect of multiple extrinsic cues on quality perceptions: A matter of consistency”, Journal of Consumer Research, Vol. 32 No. 3, pp. 146-153.

Osgood, C. E., and Tannenbaum, P. H. (1955), "The principle of congruity in the prediction of attitude change", Psychological Review, Vol. 62 No. 1, pp. 42-55.

Osterhus, T. L. (1997), "Pro-social consumer influence strategies: When and how do they work?", Journal of Marketing, Vol. 61 No. 4, pp. 16-29.

Park, C. W., Jaworski, B. J., and Maclnnis, D. J. (1986), “Strategic brand concept-image management", Journal of Marketing, Vol. 16 No. 4, pp. 135-145.

Park, C. W., Milberg, S., and Lawson, R. (1991), "Evaluation of brand extensions: the role of product feature similarity and brand concept consistency", Journal of Consumer Research, Vol. 18 No. 2, pp. 185-193.

Rao, A. R., and Monroe, K. B. (1989), "The effect of price, brand name, and store name on buyers' perceptions of product quality: An integrative review", Journal of Marketing Research, Vol. 26 No. 3, pp. 351-57.

Rucker, D. D., and Galinsky, A. D. (2009), “Conspicuous consumption versus utilitarian ideals: How different levels of power shape consumer behavior", Journal of Experimental Social Psychology, Vol. 45 No. 3, pp. 549 - 555.

Seabrook, R. (2011), "Snacks for a fat planet”, available at: https://www.newyorker.com/magazine/2011/05/16/snacks-for-a-fat-planet (accessed October 2 2018). 
Strahilevitz, M., and Myers, J. (1998), "Donations to charity as purchase incentives: How well they work may depend on what you are trying to sell”, Journal of Consumer Research, Vol. 24 No. 4, pp. 434-447.

Sujan, M., Bettman, J., and Sujan, H. (1986), "Effects of consumer expectations on information processing in selling encounters", Journal of Marketing Research, Vol. 23 No. 4, pp. $346-352$.

Tatusian, T. (2013), "FDA trans fat ban: Proposal makes clear no amount is safe", available at: http://www.latimes.com/food/dailydish/la-dd-fda-trans-fats-20131107-story.html (accessed October 16 2018).

Törn, F., and Micael Dahlén (2007), "Effects of brand incongruent advertising in competitive setting”, in S. Broghini, M. A. McGrath and C. Otnes (Eds.), European Advances in Consumer Research, Vol. 8, Association for Consumer Research, Duluth (MN), pp. 234239.

Torelli, C. J., Monga, A. B., and Kaikati, A. M. (2012), “Doing poorly by doing good: Corporate social responsibility and brand concepts", Journal of Consumer Research, Vol. 38 No. 5, pp. 948-963.

White, K., MacDonnell, R., and Ellard, J. H. (2012), "Belief in a just world: Consumer intentions and behaviors toward ethical products", Journal of Marketing, Vol. 76 No. 1, pp. 103118.

Wilcox, K., Kim, H. M., and Sen, S. (2009), "Why do consumers buy counterfeit luxury brands?", Journal of Marketing Research, Vol. 46 No. 2, pp. 247-259. 
Winterich, K. P., and Barone, M. J. (2011), "Warm glow or cold, hard cash? Social identify effects on consumer choice for donation versus discount promotions", Journal of Marketing Research, Vol. 48 No. 5, pp. 855-868. 
Figures

Figure 1. The Effect of (In)Congruity Between Ethical Attributes and Brand Concept on Brand Attractiveness for Backpack and Hoodie (Study 1)

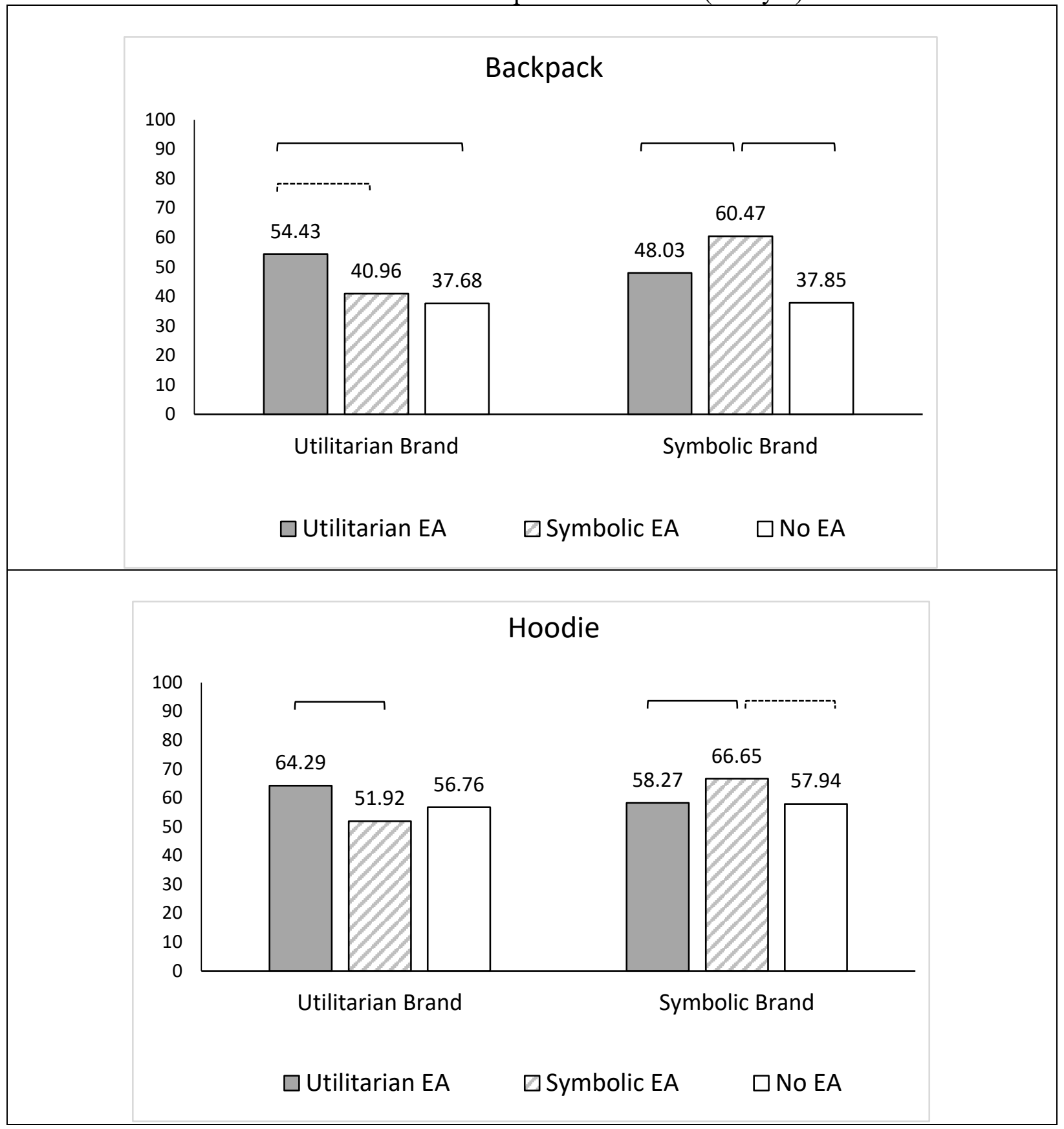

Notes: $\mathrm{EA}=$ ethical attribute. Solid brackets indicate significant differences at $\mathrm{p}<.05$ and dashed brackets at $\mathrm{p}<.10$. 
Figure 2. The Effect of (In)Congruity Between Ethical Attributes and Brand Concept on Brand Appeal for Backpack and Hoodie (Study 2)

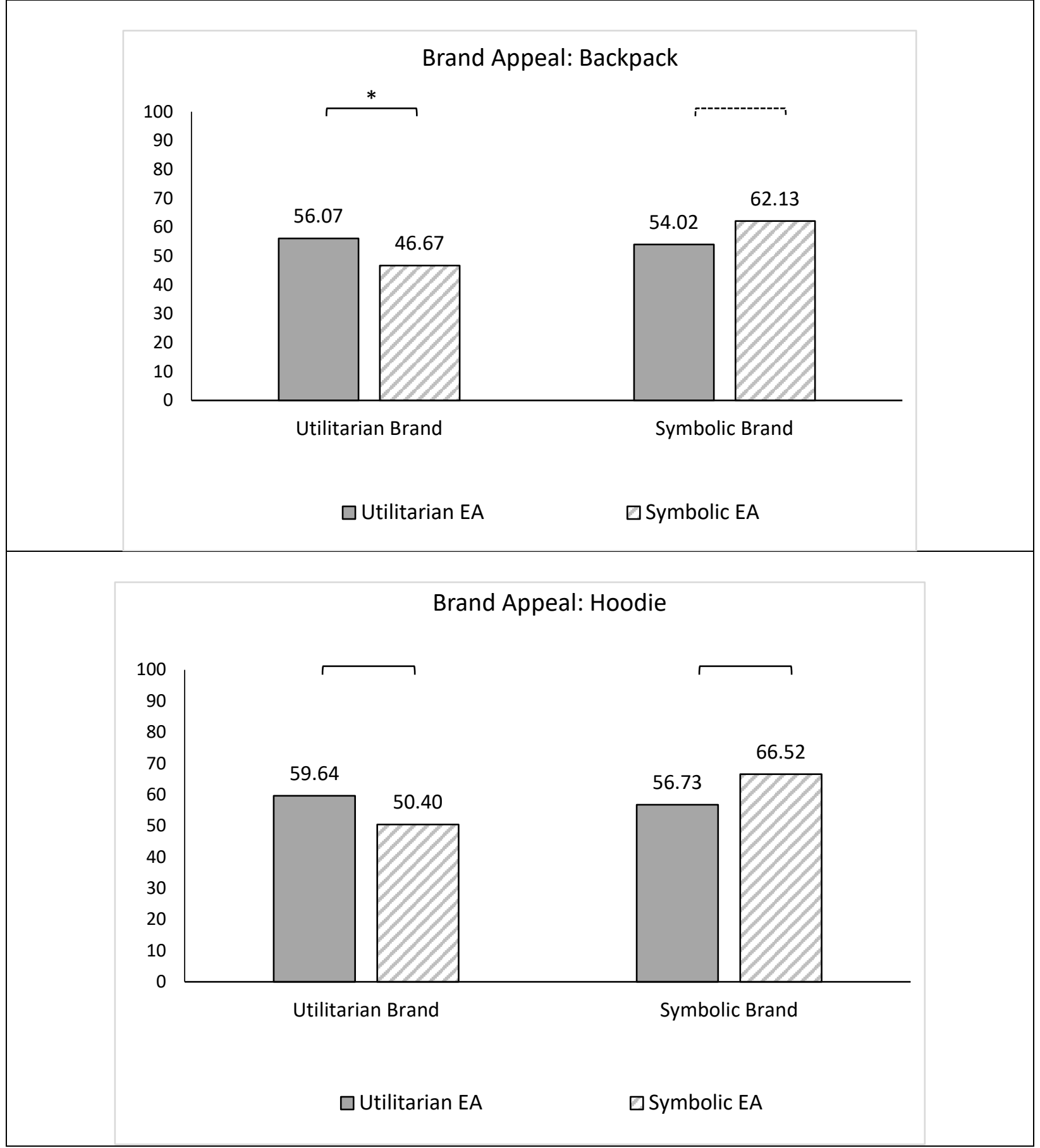

Notes: EA $=$ ethical attribute. Solid brackets indicate significant differences at $\mathrm{p}<.05$ and dashed brackets at $\mathrm{p}<.10 . *$ Significant at $\mathrm{p}=.05$ 
Figure 3. The Effect of (In)Congruity Between Ethical Attributes and Brand Concept on Brand Appeal for Carry-on Luggage (Study 3)

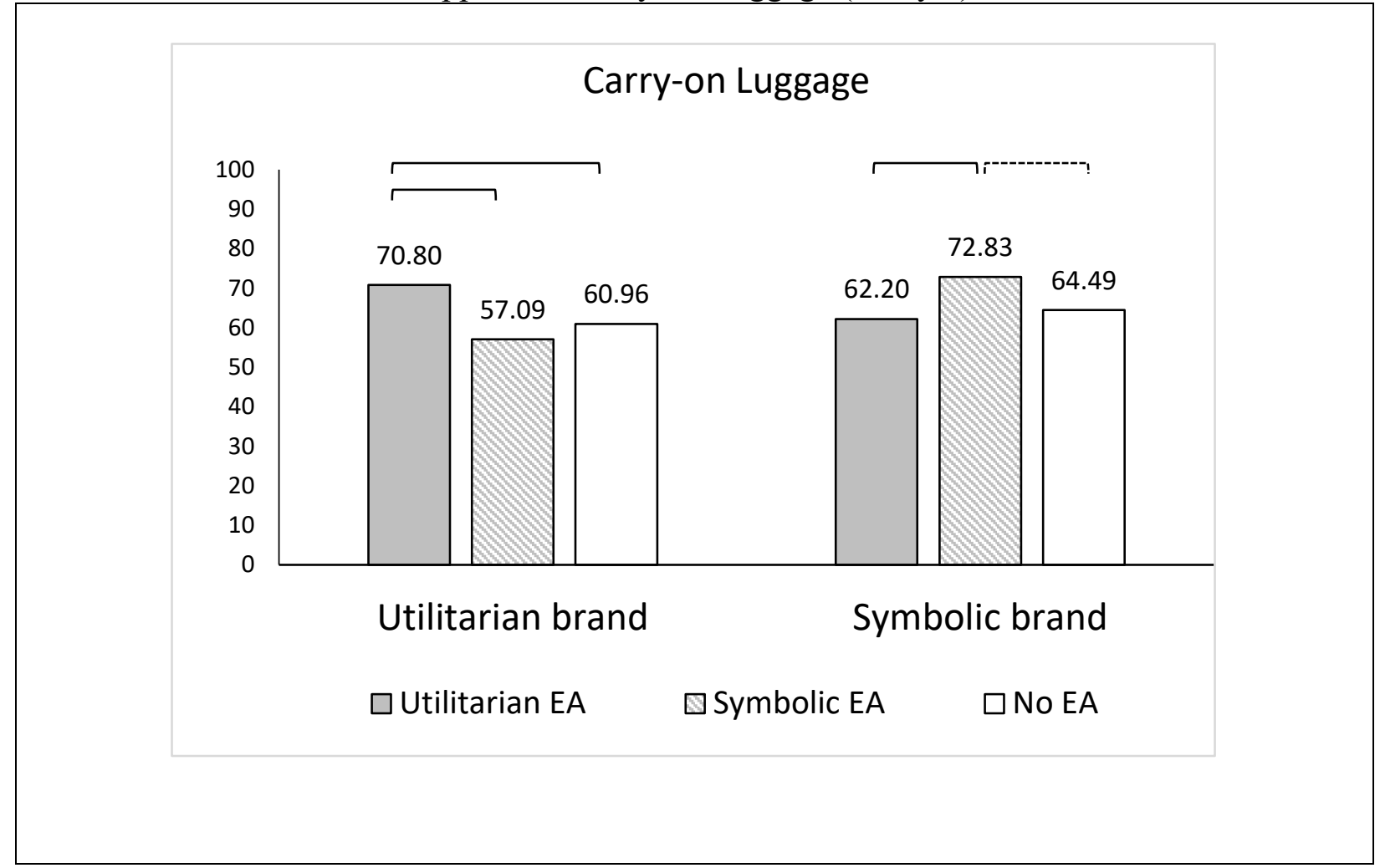

Notes: $\mathrm{EA}=$ ethical attribute. Solid brackets indicate significant differences at $\mathrm{p}<.05$ and dashed brackets at $\mathrm{p}<.10$. 
Figure 4. The Effect of (In)Congruity Between Ethical Attributes and Brand Concept on Brand Evaluation for Sport Socks (Study 4)

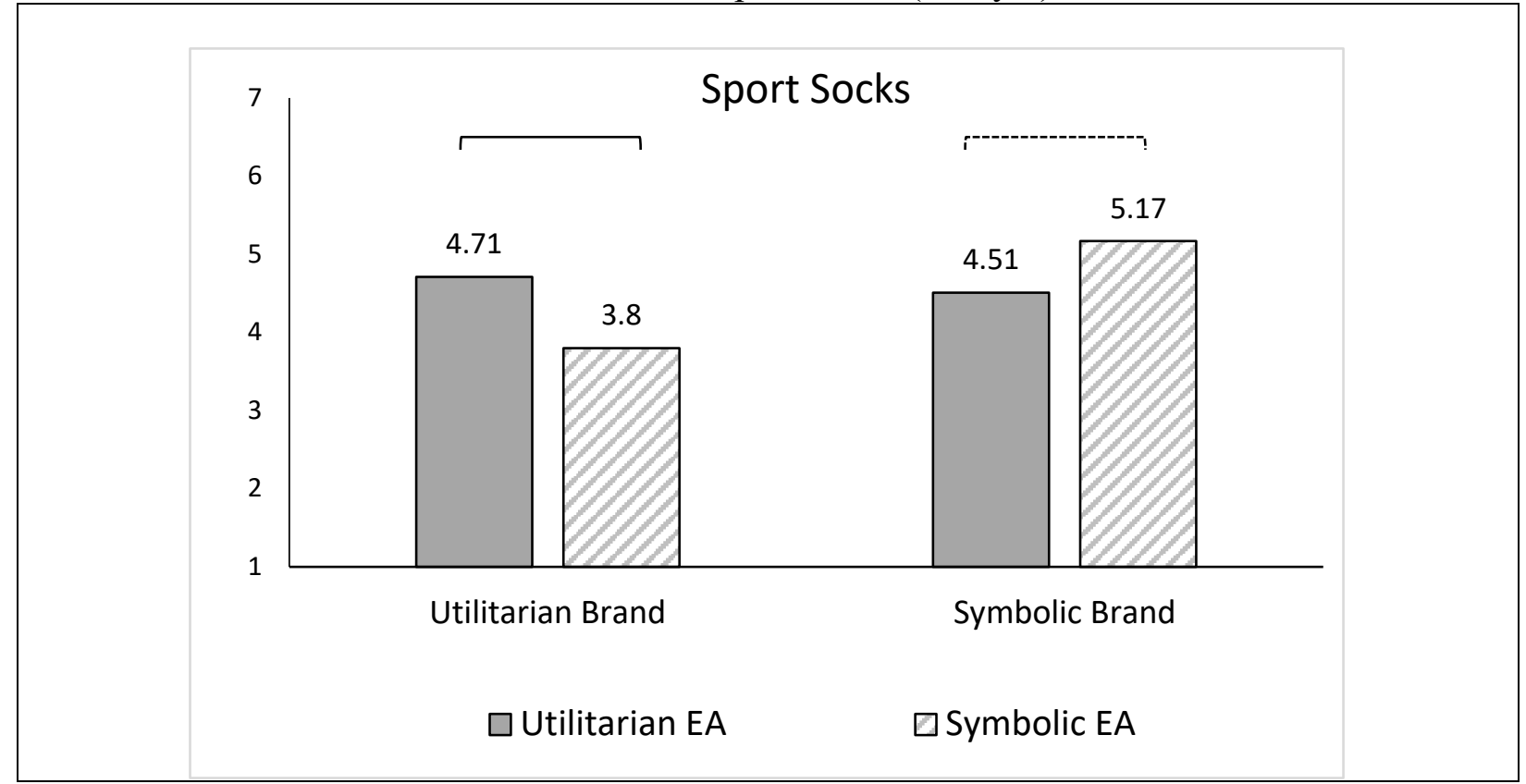

Notes: $\mathrm{EA}=$ ethical attribute. Solid brackets indicate significant differences at $\mathrm{p}=.05$ and dashed brackets at $\mathrm{p}<.10$. 
Figure 5. The Effect of Conspicuousness on the Congruity Between Ethical Attribute and Brand Concept for Sport Socks (Study 4)

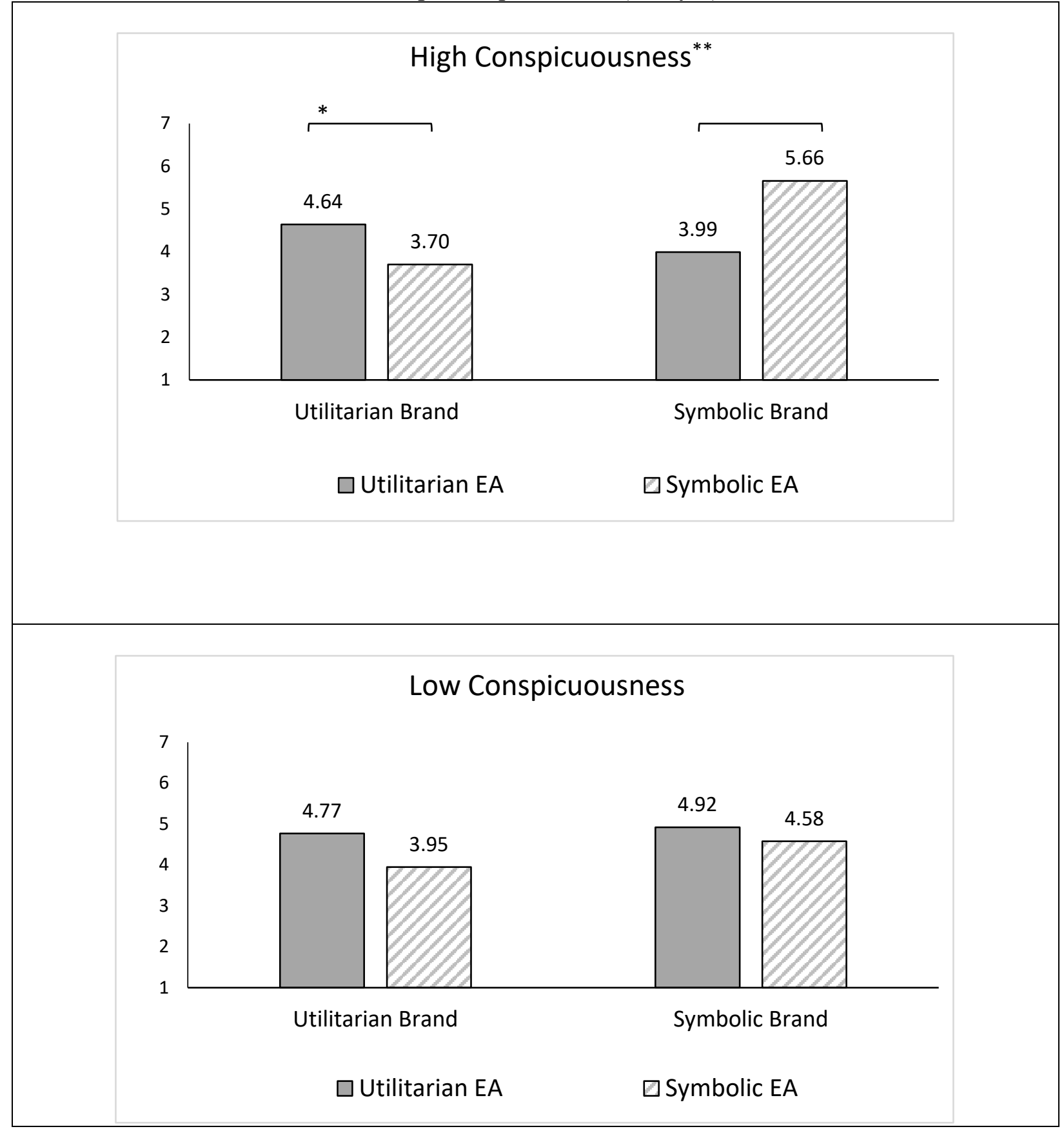

Notes: $\mathrm{EA}=$ ethical attribute. Solid brackets indicate significant differences at $\mathrm{p}<.05$ and dashed brackets at $\mathrm{p}<.10$. ${ }^{*}$ Significant at $\mathrm{p}=.05 .{ }^{* *}$ The high conspicuousness value $(B=5.25)$ was reported at $1 \mathrm{SD}$ above the mean and the low conspicuousness value $(B=2.42)$ was reported at 1SD below the mean, both derived from the PROCESS Model 3 (Hayes, 2013). 


\section{Appendix}

\section{A. Summary of Measures and Items}

\begin{tabular}{|c|c|c|c|}
\hline Construct & Item & Anchors & Source \\
\hline Brand familiarity & $\begin{array}{l}\text { How familiar are you with the } \\
\text { following brands? }\end{array}$ & $\begin{array}{l}1=\text { not at all familiar } / 9 \\
=\text { very familiar }\end{array}$ & $\begin{array}{l}\text { Bodur, Tofighi, \& } \\
\text { Grohmann (2016) }\end{array}$ \\
\hline $\begin{array}{l}\text { Utilitarian/symbolic brand } \\
\text { perception }\end{array}$ & $\begin{array}{l}\text { In your opinion, what is the main } \\
\text { benefit of [brand]? }\end{array}$ & $\begin{array}{l}1=\text { the brand is } \\
\text { functional (i.e., is } \\
\text { practical), } 9=\text { the brand } \\
\text { is symbolic (i.e., shows } \\
\text { your identity) }\end{array}$ & $\begin{array}{l}\text { Adapted from Bodur, } \\
\text { Gao, \& Grohmann } \\
(2014)\end{array}$ \\
\hline $\begin{array}{l}\text { Utilitarian/symbolic ethical } \\
\text { attribute perception }\end{array}$ & $\begin{array}{l}\text { In your opinion, what is the main } \\
\text { benefit of [attribute]? }\end{array}$ & $\begin{array}{l}1=\text { the attribute is } \\
\text { functional (i.e., is } \\
\text { practical), } 9=\text { the } \\
\text { attribute is symbolic } \\
\text { (i.e., shows your } \\
\text { identity) }\end{array}$ & $\begin{array}{l}\text { Adapted from Bodur, } \\
\text { Gao, \& Grohmann } \\
(2014)\end{array}$ \\
\hline Brand attractiveness & How attractive is the [brand/product]? & $\begin{array}{l}1=\text { extremely } \\
\text { unattractive, } 100= \\
\text { extremely attractive }\end{array}$ & $\begin{array}{l}\text { Bodur, Tofighi, \& } \\
\text { Grohmann (2016) }\end{array}$ \\
\hline Brand appeal & How appealing is the [brand/product]? & $\begin{array}{l}1=\text { extremely } \\
\text { unappealing, } 100= \\
\text { extremely appealing }\end{array}$ & $\begin{array}{l}\text { Bodur, Tofighi, \& } \\
\text { Grohmann (2016) }\end{array}$ \\
\hline $\begin{array}{l}\text { Perceived brand concept - } \\
\text { ethical attribute congruity }\end{array}$ & $\begin{array}{l}\text { To what extent do you agree that ... } \\
\text { - the [attribute] reflects what the } \\
\text { [brand] stands for. } \\
\text { - is consistent with the [brand]. }\end{array}$ & $\begin{array}{l}1=\text { strongly disagree }, 7 \\
=\text { strongly agree }\end{array}$ & $\begin{array}{l}\text { Loken \& John (1993); } \\
\text { White \& Dahl (2007) }\end{array}$ \\
\hline Brand attitude & $\begin{array}{l}\text { How would you evaluate the } \\
\text { [brand/product]? }\end{array}$ & $\begin{array}{l}1=\text { unfavorable } / \mathrm{bad} / \\
\text { negative, } 7=\text { favorable } \\
\text { /good/positive }\end{array}$ & $\begin{array}{l}\text { Batra \& Ahtola } \\
\text { (1991); Yoo \& } \\
\text { MacInnis (2005) }\end{array}$ \\
\hline $\begin{array}{l}\text { Perceived conspicuousness } \\
\text { of brand consumption }\end{array}$ & $\begin{array}{l}\text { When you are using [brand/product], } \\
\text { your product use is... }\end{array}$ & $\begin{array}{l}1=\text { visible /noticeable } \\
\text { /conspicuous/public, } 7= \\
\text { non-visible } \\
\text { /unnoticeable/ } \\
\text { inconspicuous/private }\end{array}$ & $\begin{array}{l}\text { Gierl \& Huettl (2010); } \\
\text { Rucker \& Galinsky } \\
(2009)\end{array}$ \\
\hline
\end{tabular}


B. Studies 1 - 4: ANOVA Results

\begin{tabular}{|c|c|c|c|c|}
\hline & $d f$ & F Statistics & $\boldsymbol{P}$ & $\begin{array}{c}\text { Partial Eta } \\
\text { Squared }\end{array}$ \\
\hline \multicolumn{5}{|l|}{ Study $1(\mathrm{DV}=$ Brand Attractiveness) } \\
\hline Ethical Attribute & 2 & 4.998 & $.008^{* *}$ & .052 \\
\hline Brand Concept & 1 & 2.432 & .121 & .013 \\
\hline Ethical Attribute $\times$ Brand Concept & 2 & 7.529 & $.001^{* *}$ & .076 \\
\hline \multicolumn{5}{|l|}{ Study $2(D V=$ Brand Appeal) } \\
\hline Ethical Attribute & 1 & .007 & .934 & .000 \\
\hline Brand Concept & 1 & 8.753 & $.004^{* *}$ & .047 \\
\hline Ethical Attribute $\times$ Brand Concept & 1 & 16.492 & $.000^{* *}$ & .086 \\
\hline \multicolumn{5}{|l|}{ Study 3 (DV = Brand Appeal) } \\
\hline Ethical Attribute & 2 & .678 & .509 & .006 \\
\hline Brand Concept & 1 & 1.620 & .204 & .007 \\
\hline Ethical Attribute $\times$ Brand Concept & 2 & 5.635 & $.004^{* *}$ & .046 \\
\hline \multicolumn{5}{|l|}{ Study 4 (DV = Brand Attitude) } \\
\hline Ethical Attribute & 1 & .267 & .606 & .003 \\
\hline Brand Concept & 1 & 6.024 & $.016^{*}$ & .057 \\
\hline Ethical Attribute $\times$ Brand Concept & 1 & 11.026 & $.001^{* *}$ & .099 \\
\hline
\end{tabular}

${ }^{*}$ Significant at $p<.05 .{ }^{* *}$ Significant at $p<.01 .{ }^{\mathrm{ms}}$ Marginally Significant at $p<.1$. 
C. Studies $1-4$ : Descriptive Statistics and Pairwise Comparisons

\begin{tabular}{|c|c|c|c|c|c|c|c|c|c|c|c|}
\hline & & & \multicolumn{2}{|c|}{$\begin{array}{c}\text { Descriptive } \\
\text { Statistics }\end{array}$} & \multicolumn{4}{|c|}{$\begin{array}{c}\text { Descriptive } \\
\text { Statistics }\end{array}$} & \multicolumn{3}{|c|}{ ANOVA Test } \\
\hline & & & Mean & $S D$ & & Mean & $S D$ & $\begin{array}{c}\text { Mean } \\
\text { Difference }\end{array}$ & $\begin{array}{c}F \\
\text { Statistics }\end{array}$ & $P$ & $\begin{array}{c}\text { Partial } \\
\text { Eta } \\
\text { Squared }\end{array}$ \\
\hline & $\begin{array}{c}\text { Brand } \\
\text { Concept }\end{array}$ & $\begin{array}{l}\text { Ethical } \\
\text { Attribute }\end{array}$ & & & $\begin{array}{l}\text { Ethical } \\
\text { Attribute }\end{array}$ & & & & & & \\
\hline \multicolumn{12}{|l|}{ Study 1} \\
\hline \multirow[t]{4}{*}{ Backpack } & Utilitarian & Utilitarian & 54.43 & 23.16 & Symbolic & 40.96 & 24.65 & 13.47 & 4.117 & $.045^{*}$ & .034 \\
\hline & & & & & Control & 37.68 & 29.05 & 16.75 & 6.242 & $.014^{*}$ & .048 \\
\hline & Symbolic & Symbolic & 60.47 & 24.31 & Utilitarian & 48.03 & 25.19 & 12.44 & 4.364 & $.039^{*}$ & .036 \\
\hline & & & & & Control & 37.85 & 26.78 & 22.62 & 12.329 & $.001^{* *}$ & .091 \\
\hline \multirow[t]{4}{*}{ Hoodie } & Utilitarian & Utilitarian & 64.29 & 13.81 & Symbolic & 51.92 & 22.50 & 12.63 & 7.150 & $.009^{* *}$ & .058 \\
\hline & & & & & Control & 56.76 & 19.56 & 7.52 & 2.584 & .110 & .020 \\
\hline & Symbolic & Symbolic & 66.65 & 12.74 & Utilitarian & 58.27 & 18.16 & 8.37 & 4.148 & $.046^{*}$ & .034 \\
\hline & & & & & Control & 57.94 & 20.42 & 8.71 & 3.552 & $.062^{\mathrm{ms}}$ & .028 \\
\hline \multicolumn{12}{|l|}{ Study 2} \\
\hline \multirow[t]{2}{*}{ Backpack } & Utilitarian & Utilitarian & 56.07 & 25.73 & Symbolic & 46.67 & 20.82 & 9.40 & 3.861 & $.051^{*}$ & .021 \\
\hline & Symbolic & Symbolic & 62.13 & 17.51 & Utilitarian & 54.02 & 25.80 & 8.11 & 2.871 & $.092^{\mathrm{ms}}$ & .016 \\
\hline \multirow[t]{2}{*}{ Hoodie } & Utilitarian & Utilitarian & 59.64 & 21.38 & Symbolic & 50.40 & 23.11 & 9.24 & 4.116 & $.044^{*}$ & .023 \\
\hline & Symbolic & Symbolic & 66.52 & 21.03 & Utilitarian & 56.73 & 20.86 & 9.79 & 4.618 & $.033^{*}$ & .026 \\
\hline \multicolumn{12}{|l|}{ Study 3} \\
\hline \multirow[t]{4}{*}{ Carry-on } & Utilitarian & Utilitarian & 70.80 & 16.29 & Symbolic & 57.09 & 21.46 & 13.71 & 9.27 & $.003^{* *}$ & .064 \\
\hline & & & & & Control & 60.96 & 24.66 & 9.84 & 3.98 & $.048^{*}$ & .023 \\
\hline & Symbolic & Symbolic & 72.83 & 14.03 & Utilitarian & 62.20 & 21.58 & 10.63 & 5.83 & $.017^{*}$ & .041 \\
\hline & & & & & Control & 64.49 & 24.58 & 8.34 & 2.98 & $.086^{\mathrm{ms}}$ & .017 \\
\hline \multicolumn{12}{|l|}{ Study 4} \\
\hline \multirow[t]{2}{*}{$\begin{array}{l}\text { Sport } \\
\text { Socks }\end{array}$} & Utilitarian & Utilitarian & 4.71 & 1.11 & Symbolic & 3.80 & 1.33 & .91 & 7.637 & $.007^{* *}$ & .071 \\
\hline & Symbolic & Symbolic & 5.17 & 1.16 & Utilitarian & 4.51 & 1.25 & .67 & 3.794 & $.054^{*}$ & .037 \\
\hline
\end{tabular}

"Significant at $p<.05 .{ }^{* *}$ Significant at $p<.01 .{ }^{\mathrm{ms}}$ Marginally Significant at $p<.1$. 
D. Study 4: Descriptive Statistics and Pairwise Comparisons by Brand Conspicuousness

\begin{tabular}{ccccccc}
\hline & Brand & EA & Mean & EA & Mean & $\begin{array}{c}\text { Mean } \\
\text { Difference }\end{array}$ \\
\hline \multirow{2}{*}{$\begin{array}{c}\text { Sport } \\
\text { Socks }\end{array}$} & Utilitarian & Utilitarian & 4.64 & Symbolic & 3.70 & .94 \\
& Symbolic & Symbolic & 5.66 & Utilitarian & 3.99 & 1.67 \\
\hline \multirow{2}{*}{$\begin{array}{c}\text { Sport } \\
\text { Socks }\end{array}$} & Utilitarian & Utilitarian & 4.77 & Symbolic & 3.95 & .82 \\
& Symbolic & Symbolic & 4.92 & Utilitarian & 4.58 & .34 \\
\hline
\end{tabular}


E. Studies 2 and 3: Mediating Role of Perceived Congruity

\begin{tabular}{|c|c|c|c|c|c|c|}
\hline & Coef & S.E. & $t$ & $p$ & $L L C I$ & $U L C I$ \\
\hline \multicolumn{7}{|l|}{ Study 2 (Backpack) } \\
\hline $\begin{array}{l}\text { Brand Concept } \times \text { Ethical } \\
\text { Attribute } \rightarrow \text { Perceived } \\
\text { Congruity }\end{array}$ & .25 & .10 & 2.63 & .01 & .06 & .44 \\
\hline $\begin{array}{l}\text { Perceived Congruity } \rightarrow \text { Brand } \\
\text { Appeal }\end{array}$ & 2.97 & 1.31 & 2.26 & .03 & .38 & 5.55 \\
\hline $\begin{array}{l}* \text { Brand Concept } \times \text { Ethical } \\
\text { Attribute } \rightarrow \text { Brand Appeal }\end{array}$ & .75 & .47 & -- & -- & .09 & 1.97 \\
\hline $\begin{array}{l}\text { Utilitarian Brand } \times \text { Ethical } \\
\text { Attribute } \rightarrow \text { Brand Appeal }\end{array}$ & -.87 & .61 & -- & -- & -2.69 & -.07 \\
\hline $\begin{array}{l}\text { Symbolic Brand } \times \text { Ethical } \\
\text { Attribute } \rightarrow \text { Brand Appeal }\end{array}$ & .63 & .50 & -- & -- & .05 & $1.79 * * *$ \\
\hline $\begin{array}{l}* * \text { Brand Concept } \times \text { Ethical } \\
\text { Attribute } \rightarrow \text { Brand Appeal }\end{array}$ & 3.63 & 1.70 & 2.13 & .035 & .26 & 6.99 \\
\hline $\begin{array}{l}\text { Utilitarian Brand } \times \text { Ethical } \\
\text { Attribute } \rightarrow \text { Brand Appeal }\end{array}$ & -3.83 & 2.40 & -- & -- & -8.56 & .90 \\
\hline $\begin{array}{l}\text { Symbolic Brand } \times \text { Ethical } \\
\text { Attribute } \rightarrow \text { Brand Appeal }\end{array}$ & 3.43 & 2.38 & -- & -- & -1.27 & 8.13 \\
\hline \multicolumn{7}{|l|}{ Study 2 (Hoodie) } \\
\hline $\begin{array}{l}\text { Brand Concept } \times \text { Ethical } \\
\text { Attribute } \rightarrow \text { Perceived } \\
\text { Congruity }\end{array}$ & .37 & .08 & 4.52 & .00 & .21 & .53 \\
\hline $\begin{array}{l}\text { Perceived Congruity } \rightarrow \text { Brand } \\
\text { Appeal }\end{array}$ & 3.03 & 1.48 & 2.05 & .04 & .11 & 5.95 \\
\hline $\begin{array}{l}* \text { Brand Concept } \times \text { Ethical } \\
\text { Attribute } \rightarrow \text { Brand Appeal }\end{array}$ & 1.12 & .66 & -- & -- & .03 & 2.61 \\
\hline $\begin{array}{l}\text { Utilitarian Brand } \times \text { Ethical } \\
\text { Attribute } \rightarrow \text { Brand Appeal }\end{array}$ & -1.04 & .68 & -- & -- & -2.77 & -.06 \\
\hline $\begin{array}{l}\text { Symbolic Brand } \times \text { Ethical } \\
\text { Attribute } \rightarrow \text { Brand Appeal }\end{array}$ & 1.19 & .75 & -- & -- & .05 & 3.08 \\
\hline $\begin{array}{l}* * \text { Brand Concept } \times \text { Ethical } \\
\text { Attribute } \rightarrow \text { Brand Appeal }\end{array}$ & 3.64 & 1.69 & 2.16 & .03 & .31 & 6.97 \\
\hline $\begin{array}{l}\text { Utilitarian Brand } \times \text { Ethical } \\
\text { Attribute } \rightarrow \text { Brand Appeal }\end{array}$ & -3.58 & 2.31 & -- & -- & -8.15 & .99 \\
\hline $\begin{array}{l}\text { Symbolic Brand } \times \text { Ethical } \\
\text { Attribute } \rightarrow \text { Brand Appeal }\end{array}$ & 3.71 & 2.33 & -- & -- & -.89 & 8.31 \\
\hline \multicolumn{7}{|l|}{ Study 3 (Carry-on Luggage) } \\
\hline $\begin{array}{l}\text { Brand Concept } \times \text { Ethical } \\
\text { Attribute } \rightarrow \text { Perceived } \\
\text { Congruity }\end{array}$ & .27 & .11 & 2.50 & .01 & .09 & .44 \\
\hline $\begin{array}{l}\text { Perceived Congruity } \rightarrow \text { Brand } \\
\text { Appeal }\end{array}$ & 4.31 & 1.22 & 3.53 & .00 & 1.89 & 6.73 \\
\hline $\begin{array}{l}* \text { Brand Concept } \times \text { Ethical } \\
\text { Attribute } \rightarrow \text { Brand Appeal }\end{array}$ & 1.15 & .73 & -- & -- & .11 & 3.07 \\
\hline $\begin{array}{l}\text { Utilitarian Brand } \times \text { Ethical } \\
\text { Attribute } \rightarrow \text { Brand Appeal }\end{array}$ & -1.13 & .93 & -- & -- & -3.30 & -.05 \\
\hline Symbolic Brand $\times$ Ethical & 1.17 & .85 & -- & -- & .02 & 3.43 \\
\hline
\end{tabular}


Attribute $\rightarrow$ Brand Appeal

**Brand Concept $\times$ Ethical

Attribute $\rightarrow$ Brand Appeal

$\begin{array}{llllll}1.15 & .73 & -- & -- & .11 & 3.07\end{array}$

Utilitarian Brand $\times$ Ethical

Attribute $\rightarrow$ Brand Appeal

$\begin{array}{llllll}-5.73 & 2.18 & -- & -- & -10.05 & -1.41\end{array}$

Symbolic Brand $\times$ Ethical

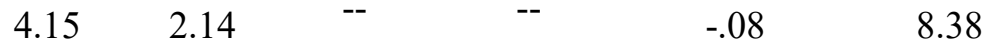

Attribute $\rightarrow$ Brand Appeal

*Indirect Effect of Brand Concept $\times$ Ethical Attribute on Outcome Variable

$* *$ Direct Effect of Brand Concept $\times$ Ethical Attribute on Outcome Variable when controlling for Perceived Congruity

***Marginally Significant at $90 \%$ CI 
F. Study 4: Moderating Effect of Brand Usage Conspicuousness

\begin{tabular}{ccccc}
\hline & Coef & S.E. & $\boldsymbol{t}$ & $\boldsymbol{p}$ \\
\hline $\begin{array}{l}\text { Study } 4 \text { (Sport Socks) } \\
\text { Brand Concept } \times \text { Ethical Attribute } \times\end{array}$ & .19 & .085 & 2.22 & .0289 \\
$\begin{array}{c}\text { Conspicuousness } \rightarrow \text { Brand Evaluation } \\
\text { High Conspicuousness (+1 SD = 5.25) } \\
\text { Brand Concept } \times \text { Ethical } \\
\text { Attribute } \rightarrow \text { Brand Evaluation }\end{array}$ & +.65 & .16 & 3.96 & .0001 \\
\hline $\begin{array}{c}\text { Low Conspicuousness (-1 SD = 2.42) } \\
\text { Brand Concept } \times \text { Ethical } \\
\text { Attribute } \rightarrow \text { Brand Evaluation }\end{array}$ & .12 & & & \\
\hline
\end{tabular}

